\title{
Near-Lean Blowoff Dynamics in a Liquid Fueled Combustor
}

\author{
Nicholas Rock, Ben Emerson, Jerry Seitzman, Tim Lieuwen \\ Ben T. Zinn Combustion Laboratory \\ Georgia Institute of Technology, Atlanta GA, 30318, USA
}

\section{Corresponding Author}

Tim Lieuwen

Ben T. Zinn Combustion Laboratory

Georgia Institute of Technology

Atlanta, GA 30318

Phone: 678-642-7892

Email: tim.lieuwen@aerospace.gatech.edu

Declarations of interest: none

Keywords: Lean Blowout (LBO); Alternative Jet fuels; Derived Cetane Number (DCN);

Extinction; Re-ignition 
Technical Report Documentation Page

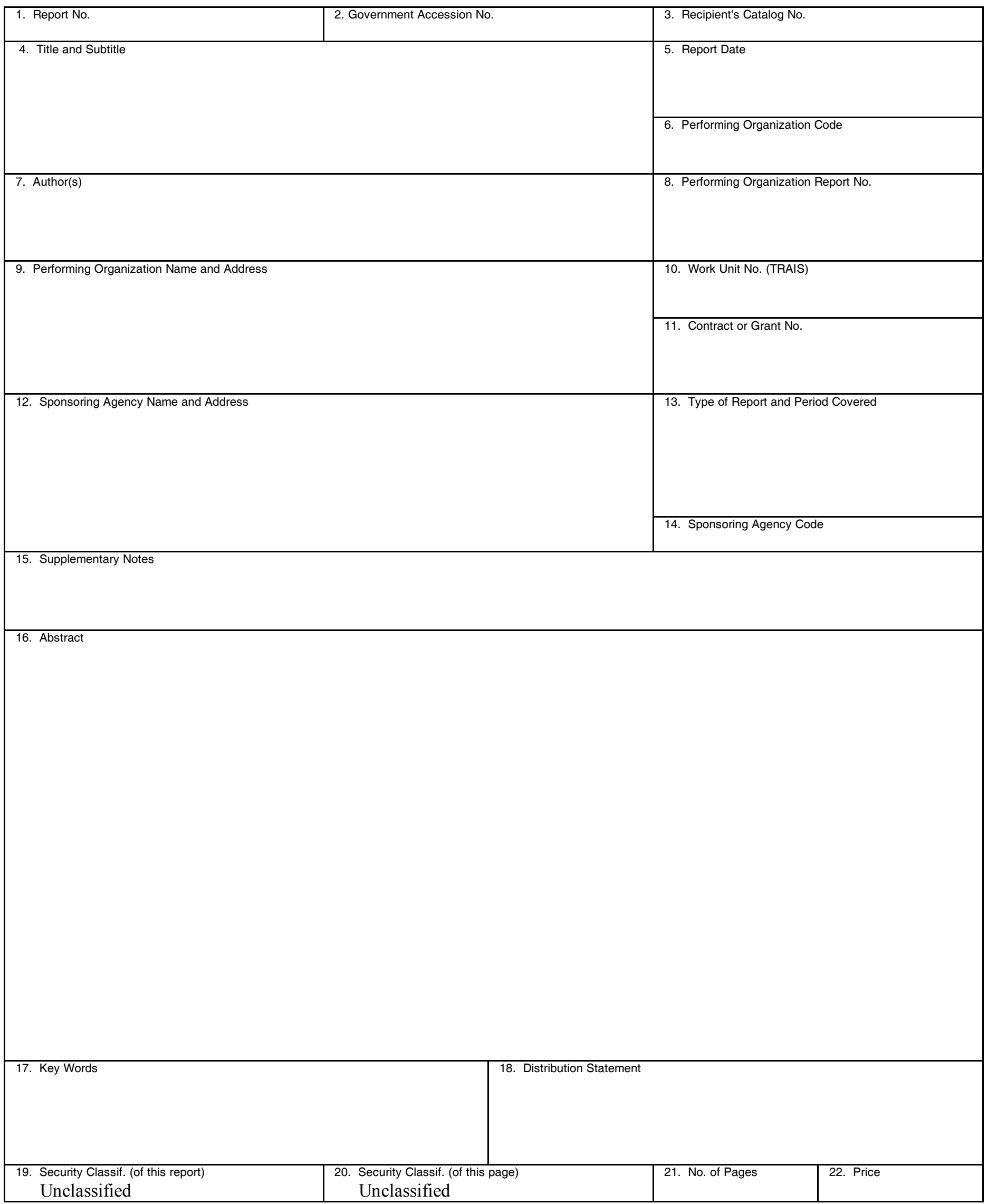

Form DOT F 1700.7 (8-72)

Reproduction of completed page authorized 


\title{
Near-Lean Blowoff Dynamics in a Liquid Fueled Combustor
}

\author{
Nicholas Rock, Ben Emerson, Jerry Seitzman, Tim Lieuwen \\ Ben T. Zinn Combustion Laboratory \\ Georgia Institute of Technology, Atlanta GA, 30318, USA
}

\begin{abstract}
This paper describes an analysis of the near-lean blow off (LBO) dynamics of spray flames, including the influence of fuel composition upon these dynamics. It is motivated by the fact that, while reasonable correlations exist for predicting blowoff conditions, the fundamental reasons for why flames supported by flow recirculation actually blowoff are not well understood. Prior work on gaseous systems has shown that the blowoff event is a culmination of several intermediate processes, initiating with local extinction of reactions ("stage 1"), followed by large scale changes in flame and flow dynamics ("stage 2"), finally leading to blowoff. In this study, near-LBO dynamics were characterized for ten liquid fuels with widely varying kinetic and physical properties. Results were compared at two air inlet temperatures, 450 and $300 \mathrm{~K}$, as this influences the relative importance of physical and kinetic properties in controlling LBO. Extinction, re-ignition, and recovery of the flame are evident from these data, and grow in frequency as blowoff is approached. Results show that after a near-blowoff event, the flame can move upstream at velocities much faster than the flow velocity, corresponding to re-ignition. Nonetheless, the majority of the flame recovery events appear to be associated with convection of hot products back upstream, not re-ignition. In contrast, downstream motion of the flame faster than the flow, which would correspond to bulk flame extinction, was never observed. This indicates that "extinction events" actually correspond to convection of the flame downstream by the flow, when it loses its stabilization point. The dependence of the equivalence ratio when these events appear, their frequency, and event duration were quantified as a function of fuel composition and air inlet temperature. For example, the data shows a higher percentage of recovery from near-blowoff events through re-ignition for high DCN fuels at the $450 \mathrm{~K}$ air temperature condition. These extinction/re-ignition results suggest that high DCN fuels are harder to blowoff than low DCN fuels through two mechanisms (1) by delaying the onset of LBO precursor events, and (2) because they are able to recover from these precursor events through re-ignition more often.
\end{abstract}




\section{Introduction}

This paper describes an experimental study of the role of fuel properties on spray flame dynamics under near-lean blowoff conditions and compares these results with previous work relating fuel properties to blowoff boundaries. It is motivated by an interest in understanding how liquid fueled combustors' blowoff boundaries are influenced by alternative fuel composition. The use of alternative fuels is motivated by concerns over global climate change, local air quality, limited petroleum resources, and a desire to reduce transportation costs. However, the current process to certify new aircraft engine fuels is costly and time consuming, which discourages investment in alternative fuels [1]. Jet fuels are evaluated by both emissions and operability standards, among which are altitude re-light, cold start, and lean blowoff.

Chemical kinetic rates, ignitability, fuel-air mixing quality, atomization, and the vaporization characteristics of a fuel can all influence blowoff limits. The dominant limiting process depends on the type of combustion system and the operating conditions. Specifically, gaseous premixed, gaseous nonpremixed, and liquid fueled systems can all have different LBO sensitivities to fuel properties, ambient conditions, and injector geometry. For example, in liquid fueled systems, the effect of fuel composition varies with air inlet temperature, as this controls the relative roles of physical and kinetic properties. Moreover, in systems stabilized by hot gas recirculation, blowoff is not so much an event as it is the culmination of a series of processes (as detailed further in this section) - in other words, the flame can exist under very severe local conditions in terms of strain rate or scalar dissipation rate because of the piloting action of hot recirculating fluid. However, the temperature and composition of these recirculating gases are also functions of the conditions at the flame. As such, the problem has intrinsic feedback, time delays, and is strongly coupled to the recirculating fluid time scales.

Starting with premixed gaseous systems, Damköhler number scalings (i.e., the ratio of characteristic fluid mechanic and chemical kinetic time) have been successful in predicting their blowoff limits. This has been demonstrated with data taken using different operating conditions, fuel types, and combustor geometries. Multiple physical models have been proposed in the literature for determining the characteristic chemical time used to calculate the Damköhler number, including ignition times, extinction times, and flame propagation times; e.g., see Zukoski [2] [3], Longwell [4], Zhang et al. [5], and Shanbhogue et al. [6]. 
Fuel-air mixing physics must also be considered in the stabilization of nonpremixed flames, along with an increased emphasis on edge flames. In a review article by Lyons [7], five paradigms are used to describe the stability of nonpremixed flames. They include (1) a premixed flame stabilizing the base of the nonpremixed flame, (2) stabilization by diffusion flamelets below a critical scalar dissipation rate, (3) turbulence intensity increasing the burning velocity at the flame leading edge, (4) transport of the flame leading edge upstream by large eddies, and (5) a partially premixed edge flame stabilizing the base of the nonpremixed flame. In turn, these limits are sensitive to extinction scalar dissipation rates and stretch rates for nonpremixed and premixed leading edges, as well as flame speeds for triple point or premixed flames.

Liquid fueled combustors are the most relevant configuration for aircraft applications. In addition to chemistry and mixing effects, blowoff is also influenced by atomization and vaporization processes. Available data often generate conflicting or inconclusive results [8-15], likely due to the range of potentially dominant physical processes depending upon atomization quality, air preheat temperature, etc. Early approaches to this problem involved generalizing methods developed from premixed combustors. For example, Mellor [9] added an extra term, accounting for droplet evaporation effects, to a time scale correlation that was developed for premixed systems. Lefebvre [8] developed a similar empirical expression that was based on the combustor geometry, operating conditions, and fuel physical properties. Lefebvre also made the interesting point that improved atomization quality can contract blowoff boundaries; e.g., injectors with poor atomization quality could be advantageous for flame stability because they allowed combustion to occur at equivalence ratios well below the perfectly premixed stability limit. These ideas are supported by Peters [16], Mellor [9], and the recent experimental data of Grohmann et al. [13].

As noted above, liquid fueled systems' blowoff boundaries are influenced by both physical and kinetic properties of the fuel. The work of Burger et al. [12] also found blowoff to correlate well with fuel vaporization characteristics, showing that easily vaporized fuels were the most blowoff resistant. Grohmann et al. [13] found the same sensitivity, but in the opposite direction; i.e., hard to vaporize fuels were the most blowoff resistant. Other studies have noted kinetic sensitivities to LBO boundaries. For example, Colket et al. [10], Stouffer et al. [14], and Allision et al. [17] found that blowoff boundaries could be correlated with the derived cetane number (DCN), a kinetic property. Although the DCN is directly related to the mixture's ignition delay 
time [18], it is also correlated with high-temperature kinetic properties, such as the flame speed and the extinction stretch rate [19]. For this reason, the DCN has often been used as a measure of global chemical kinetic reactivity [20-24]. This creates some uncertainty, however, in the conclusions that can be drawn about the underlying physics that govern the observed correlations between the DCN and $\phi_{L B O}$. The superior extinction stretch rate, flame speed, and autoignition characteristics of high DCN fuels could all be beneficial in resisting LBO. Therefore, it is difficult to know which of these physical processes actually limits blowoff - flame speeds, stretch-induced extinction, or autoignition.

A recent publication by the authors tested 18 different liquid fuels at air inlet temperatures of $300 \mathrm{~K}, 450 \mathrm{~K}$, and $550 \mathrm{~K}$ [25]. This range of operating temperatures spanned the air temperatures previously tested in the literature. The group of liquid fuels that were tested included both currently certified jet fuels, surrogates with simpler compositions that are more amenable to modeling [26], and other fuels which were designed to isolate the effect of a particular fuel property on lean blowout. Currently certified jet fuels were named the "A" fuels, the " $\mathrm{S}$ " fuels represent the surrogate fuels, and the " $\mathrm{C}$ " fuel nomenclature is used to describe fuels that were designed to evaluate specific fuel property effects. A summary of the findings from this study is shown in Figure 1, where the blowout boundaries are plotted against the DCN at $450 \mathrm{~K}$ (left) and the $90 \%$ boiling point temperature, $\mathrm{T}_{90}$, at $300 \mathrm{~K}$ (right). The DCN correlated best with the blowoff fuel-air ratios at $450 \mathrm{~K}$ and $550 \mathrm{~K}$. The few fuels that didn't follow the DCN correlation (e.g., S2) have strong preferential vaporization characteristics; incorporating these effects into these correlations substantially improves the correlation [19, 25]. Consistent with the findings of Burger et al. [12], blowoff correlated best with fuel vaporization processes at $300 \mathrm{~K}$. At this lower air temperature, the low $\mathrm{T}_{90}$ fuels were the most blowoff resistant and the high $\mathrm{T}_{90}$ fuels blew out the easiest. As the atomization characteristics of these fuels would presumably influence lean blowout boundaries, several studies [27-30], which were coordinated with the present work to use a similar pressure atomizing, filming type fuel injector, have also measured the mean droplet sizes and distributions of the tested fuels. These droplet sizing measurements found no correlation between fuel physical properties and droplet sizes for the tested pressure atomizer injector. Furthermore, the fuel properties that would influence both the spray characteristics and the transient response of the spray to the reduction in fuel flow rate approaching blowoff, namely the surface tension, viscosity, and density, failed to correlate 
strongly with lean blowout at any of the air temperatures. Taken together, these results suggest that any differences in atomization characteristics between the tested fuels do not materially influence lean blowout for this type of injector.

These different conclusions are a manifestation of the additional physical processes that can be controlling in liquid fueled systems and likely reflect differences in combustor hardware, operating conditions, and issues surrounding the association of blowoff causality with fuel properties $[8,15,31]$. For example, lower atomization quality injectors will inherently emphasize vaporization/atomization characteristics of the flame, while better atomizing systems may push the system closer towards premixed, kinetically limited characteristics. Similarly, the Rock et al. [25] data show how the controlling processes change with air temperature, presumably for similar reasons related to how quickly the fuel vaporizes .

Having considered the processes that control blowoff, consider next the dynamics of flames as they approach blowoff. In premixed systems, it is known that flames go through multiple stages as the flame approaches blowoff. Figure 2 shows a conceptual illustration of these points. As the flow/mixture conditions are changed to move the system towards blowoff, the combustor first passes through "stage 1", where local extinction occurs on the flame but the flame overall resembles its features from well-stabilized conditions [6, 32-34]. The fraction of time that local extinction occurs increases as blowoff is approached. However, the flame can persist indefinitely under such conditions, as re-ignition processes follow local extinction in "stage 1". As the flame is brought closer to blowoff, major alteration of the flow structures and flame position occurs, referred to as "stage 2". For example, in bluff-body stabilized flames, "stage 2" is manifested by a complete change in the vortical dynamics of the wake [32, 35, 36]. Furthermore, as the equivalence ratio decreases towards its blowoff value, the flame speed decreases accordingly and the flame moves inward toward low velocity regions in the shear layers [33, 37-39]. Opposing sides of the flame move towards each other near the downstream end of the bluff-body recirculation zone, where it eventually extinguishes [6, 37-41], a point that will be revisited later. Combustion only occurs in the recirculation zone, which is sometimes referred to as the "residual flame". Continued reactant entrainment cools the residual flame such that the recirculation zone eventually becomes a soup of fresh reactants, partially burned reactants, and local heat release parcels that are unable to ignite the incoming mixture [37, 42, 43]. 
Characterizing "stage 2" in swirl flames is complicated by different degrees to which changes in the vortex breakdown process occur. Muruganandam [44] and Prakash et al. [45] have observed that as the heat release decreases near blowout, due to local extinction and entrained reactants in the inner recirculation zone, the vortex breakdown mechanism changed from a bubble type to a spiral/helical type. Zhang [46] showed that these vortex breakdown changes are dependent on fuel composition, as this controls the amount of thermal expansion across the flame. However, it is difficult to make general inferences about heat release effects on vortex breakdown dynamics [47], as existing data shows that they are dependent on the combustor geometry and operating conditions involved.

As noted above, studies have shown that the stability of premixed systems can be correlated with bulk ratios of chemical and flow time scales [3, 4, 9, 48]. Given the above points, however, it is clear that multiple kinetic processes (e.g., both extinction and re-ignition) and fluid mechanic (e.g., the fluid mechanic straining time scales appear to be different in "stage 1" and "stage 2") influence the ultimate blowoff event. Shanbogue et al. [6] suggested that correlations of blowoff with a single chemical/flow time scale (as described earlier in this section), likely capture the physics associated with the extinction processes that happen near blowoff, and not blowoff itself- i.e., they are correlations for the onset of "stage 1" [6]. This is an important distinction, as the flame can exist near blowoff with significant local extinction events apparently indefinitely; i.e., while extinction and blowoff are related, they are quite distinct. Indeed, this paper will show that the difference in equivalence ratio between when stage 1 starts and when blowoff finally occurs can vary with fuel composition.

The near-blowoff dynamics of nonpremixed flames primarily involve the initiation of, and recovery from, flame holes. OH-PLIF measurements by Juddoo and Masri [49] showed that increasing the fuel jet velocity was accompanied by enhanced local extinction that eventually led to blowout. Hult et al. [50] found that the occurrence of local extinction is somewhat selfcorrecting, as fuel and hot products are allowed to escape through these flame holes to form partially premixed regions that can later re-ignite. Similar studies by Juddoo and Masri [49] and Steinberg et al. [51] identified two mechanisms whereby the flame can recover from local extinction. First, flame holes can heal through edge flame propagation, and second, growing kernels that initiated upstream can advect and reignite downstream regions of the flame. Steinberg et al. [51] argue that the vast majority of extinction recoveries are caused by edge 
flame propagation. However, Juddoo and Masri [49] conclude that reigition of advected kernels becomes increasingly significant as blowout is approached, and eventually becomes the dominant recovery mechanism very near blowout. A significant difference in the near-blowoff behavior between gaseous premixed and nonpremixed flames is that nonpremixed flames lift off the burner, with a liftoff height that grows as blowoff is approached. In contrast, bluff-body stabilized premixed flames permanently extinguish downstream, with this extinction region retracting toward the burner exit as blowoff is approached [6].

Both experiments [52-55] and simulations [56, 57] have shown that swirl stabilized spray flames near blowoff consist of a partially premixed flame along the spray trajectory and a nonpremixed flame in the outer recirculation zone. Although little is known about what ultimately causes lean blowout in spray flames, studies have investigated the dynamics that precede it. Verdier et al. [54] observed three different mechanisms that weakened their flame prior to blowoff: (1) large stretch rates in the shear layer locally extinguishing the inner premixed flame, (2) large, high velocity droplets penetrating and extinguishing the flame leading edge, and (3) disturbances in the outer nonpremixed flame caused by the sudden evaporation of droplets that extend into the outer recirculation zone. Yuan et al. [55] showed that extinction processes in the inner flame increase in frequency as blowoff is approached. Furthermore, Evans et al. [53] observed that the inner flame weakened and the outer flame strengthened as the incoming air velocity was increased towards the blowout value.

These ideas motivated the present study - i.e., to better understand the underlying physics controlling blowoff by determining how fuel properties influence the transient dynamics of nearblowoff flames, as opposed to prior work that has focused on correlating the actual blowoff condition itself. A similar conceptual model of pre-blowoff processes to that shown in Figure 2 has not been developed for blowoff in spray flames. For example, our prior blowoff studies evaluated correlations of fuel physical and chemical properties at the actual blowoff point. If the above described-hypothesis is correct, it may be that these correlations better describe the onset of "stage 1" where local extinction and re-ignition occurs. For this reason, data were obtained as part of this study for a subset of fuels and the actual blowoff process itself was observed, which enabled us to not only determine the condition at which blowoff occurs, but also where "stage 1" initiates. These conditions are then correlated against the same fuel physical and kinetic properties. 


\section{Facility}

The experiments for this study were conducted in the optically accessible, pressurized, spray combustor shown in Figure 3. A general overview of the experimental facility is given below and a more detailed description can be found in Rock et al. [25].

The rare capabilities of this facility allowed for combustion experiments to be performed at elevated pressure and air inlet temperature. Air enters the pressure vessel either through the swirler or through a secondary cooling passage. Compressed air that is capable of being heated to $750 \mathrm{~K}$ flows through the swirler and enters the test section. The cooling air does not participate in the combustion process, but rather cools the combustor hardware and later mixes with hot combustion products in a water-cooled exhaust section. The combustor pressure was maintained at the desired $345 \mathrm{kPa}$ value using a choked orifice in the exhaust exit. The air inlet temperature remained within $\pm 10 \mathrm{~K}$ of the $450 \mathrm{~K}$ condition, as measured by a thermocouple located $35 \mathrm{~cm}$ upstream of the dump plane. The air temperature was more difficult to keep fixed for the $300 \mathrm{~K}$ condition, due to ambient and system temperature differences between days, but generally stayed between $300-325 \mathrm{~K}$. Uncertainties in the measured air mass flow rate are approximately $2 \%$, with an instrumentation error of $0.1 \%$.

A quartz combustor liner was secured by the nozzle outlet and allowed for optical access into the test section. The temperature of this stainless-steel nozzle outlet surface was measured using four thermocouples that were positioned at the upstream boundary of the combustion chamber. The combustor pressure was measured using a static pressure transducer that was also installed in the nozzle. It had an instrumentation error of $0.08 \%$ FS and the uncertainty in its measured values was $\sim 0.4 \%$. Four $51 \mathrm{~mm}$ thick quartz windows surrounded the liner and constituted the optically accessible enclosure of the pressure vessel. The dimensions of the quartz liner and combustor windows are shown in Figure 3.

The swirler and fuel injector configuration resembles the nozzle geometry described in Cohen and Rosfjord [58], and a schematic is shown in Figure 4. As illustrated in this figure, there are two sets of swirl vanes which each create a separate passage for air to enter the test section. At the $450 \mathrm{~K}$ air inlet temperature condition, the nozzle exit velocity was $63 \mathrm{~m} / \mathrm{s}$ and the pressure drop across the swirler was approximately $6.7 \mathrm{kPa}$. The same air mass flow rate and 
combustor pressure was used for the $300 \mathrm{~K}$ air inlet temperature condition. A pressure type atomizer was used as the fuel injector.

A fuel cart was designed and built internally at Georgia Tech that allowed for up to ten fuels to be evaluated on a single experimental day. As described in Rock et al. [25], each fuel was housed in a separate cylinder and the cart was able to switch between fuels on demand. The uncertainty in the measured equivalence ratio is approximately $3 \%$.

The 10 fuels used in this study are a subset of those from the National Jet Fuels Combustion Program (NJFCP) [1, 19, 59]. Each of these fuels was carefully selected to accentuate the effect of a particular fuel property on lean blowout. Both currently certified and uncertified fuels were included in this group and their fuel properties are listed in Table 1. A detailed discussion of these fuels can be found in Refs. [1, 15, 25, 59].

The measurements taken in this study include both high speed $\mathrm{CH}^{*}$ chemiluminescence videos and $\mathrm{OH}^{*}$ times series from a photomultiplier tube (PMT). Fuels $\mathrm{C}-1, \mathrm{~A}-2$, S2 and ndodecane were included in the $450 \mathrm{~K} \mathrm{LBO}$ videos. The same fuels were used in the $300 \mathrm{~K}$ high speed videos, except fuel C-1 which was exchanged for C-5. These fuels were selected because they spanned the lean blowout limit range measured in our previous work (see Figure 1) [25]. The fuels labeled with an asterisk in Table 1 are those for which $\mathrm{CH}^{*}$ chemiluminescence videos were acquired. PMT measurements were gathered using all 10 fuels shown in Table 1.

Table 1: Fuel properties of the studied fuels, as detailed in Ref. [59]. The virtual smoke point of Haas et al. [60] is reported below for n-dodecane. Due to concerns over preferential vaporization, both the DCN of the initial $20 \%$ of the fuel volume to vaporize and the DCN based on the entire fuel composition are listed for Surrogate $2[19,25]$.

\begin{tabular}{|c|c|c|c|c|c|c|c|c|c|c|c|c|c|c|c|c|c|}
\hline Fuel & $\begin{array}{l}\mathbf{T}_{90} \\
(\mathbf{K})\end{array}$ & $\begin{array}{l}\mathbf{T}_{50} \\
(\mathbf{K})\end{array}$ & $\begin{array}{l}\mathbf{T}_{10} \\
(\mathbf{K})\end{array}$ & $|\mathrm{H} / \mathrm{C}|$ & $\begin{array}{c}\% \\
\text { Aromatics }\end{array}$ & $\begin{array}{c}\% \text { iso- } \\
\text { Paraffins }\end{array}$ & $\begin{array}{c}\% \mathrm{n}- \\
\text { Paraffins }\end{array}$ & $\begin{array}{c}\% \\
\text { Cycloalkanes }\end{array}$ & $\begin{array}{c}\text { Smoke } \\
\text { Point }(\mathbf{m m})\end{array}$ & DCN & MW & $\mathbf{R i}$ & $\begin{array}{c}\sigma @ 300 \\
\mathbf{K} \\
(\mathbf{m N} / \mathbf{m})\end{array}$ & $\begin{array}{c}\rho @ \mathbf{K} \\
\mathbf{K} \\
\left(\mathrm{kg} / \mathbf{m}^{3}\right)\end{array}$ & $\begin{array}{c}\mathbf{v} @ \mathbf{3 1 3} \\
\mathbf{K} \\
\left(\mathrm{mm}^{2} / \mathbf{s}\right)\end{array}$ & $\begin{array}{c}\text { Flash } \\
\text { Point } \\
\text { (K) }\end{array}$ & $\begin{array}{l}\text { LHV } \\
(\mathrm{MJ} / \mathrm{kg})\end{array}$ \\
\hline A-2 (Jet-A)* & 517.6 & 478.4 & 449.8 & 1.94 & 18.7 & 29.5 & 20.0 & 31.9 & 24.0 & 48.3 & 158.6 & 0.75 & 24.6 & 803.2 & 1.31 & 321 & 43.1 \\
\hline C-1* & \begin{tabular}{|l|l|}
497.4 \\
\end{tabular} & 456.3 & 451.9 & 2.16 & 0.0 & 99.6 & 0.0 & 0.1 & 34.5 & 17.1 & 178.0 & 0.70 & 23.0 & 759.7 & 1.50 & 323 & 43.9 \\
\hline C-4 & 479.5 & 452.7 & 442.4 & 2.18 & 0.4 & 98.9 & 0.2 & $\begin{array}{l}0.4 \\
\end{array}$ & 37.2 & 28.0 & 162.2 & \begin{tabular}{|l|}
0.72 \\
\end{tabular} & 22.4 & 759.2 & 1.25 & 318 & 43.8 \\
\hline C-5* & \begin{tabular}{|l|l|}
437.4 \\
\end{tabular} & 435.6 & 434.5 & 1.93 & 30.7 & 51.6 & 17.7 & 0.1 & 21.4 & 39.6 & 135.4 & 0.68 & 23.5 & 768.9 & 0.83 & 317 & 43.0 \\
\hline C-7 & 517.0 & 489.0 & 469.0 & 1.98 & 4.9 & 29.5 & 3.3 & 62.3 & N/A & 42.6 & 170.0 & 0.75 & 25.7 & 817.0 & 1.71 & 337 & 43.3 \\
\hline C-8 & 519.0 & 485.0 & 463.0 & 1.85 & 27.3 & 21.0 & 13.7 & 38.0 & N/A & 43.5 & 160.0 & 0.74 & 26.1 & 823.0 & 1.43 & 329 & 42.9 \\
\hline C-9 & 527.0 & 488.0 & 459.0 & 2.16 & 0.2 & 85.8 & 12.5 & 1.5 & N/A & 63.3 & 174.5 & 0.90 & 24.0 & 759.0 & 1.58 & 321 & 44.0 \\
\hline Surrogate $2^{*}$ & 551.0 & 507.0 & 394.0 & 1.95 & 24.9 & 22.5 & 52.6 & 0.0 & 21.1 & $19.1 / 50.6$ & \begin{tabular}{|l|}
156.9 \\
\end{tabular} & 0.78 & 24.6 & 778.0 & 1.28 & 289 & 42.9 \\
\hline High TSI & 535.7 & 474.9 & 441.8 & 1.91 & 28.8 & 53.7 & 17.6 & 0.0 & 17.6 & 48.4 & \begin{tabular}{|l|}
149.3 \\
\end{tabular} & N/A & N/A & 796.2 & N/A & N/A & N/A \\
\hline n-Dodecane* & 489.0 & 489.0 & 489.0 & 2.17 & 0.0 & 0.0 & 100.0 & 0.0 & 60.0 & 73.5 & \begin{tabular}{|l|}
170.3 \\
\end{tabular} & 1.00 & 25.0 & 753.0 & 1.29 & 344 & 44.2 \\
\hline
\end{tabular}

\section{Diagnostics}

\section{1. $\mathrm{OH}^{*}$ Chemiluminescence from PMT Measurements}

Photomultiplier tube (PMT) measurements were used to acquire $\mathrm{OH}^{*}$ chemiluminescence signals over longer time intervals than would be possible using cameras alone, allowing better estimates of event statistics near blowoff. By integrating all of the intensity in its field of view, 
the PMT outputted a single intensity point value taken at $10 \mathrm{kHz}$ over a 50 second interval. This involved beginning the measurements at an equivalence ratio of $\phi-\phi_{L B O} \approx 0.1$ and gradually reducing the fuel flow rate until blowoff occurred. These cases are labeled conditions A (450 K) and B $(300 \mathrm{~K})$ in Table 2. The Hamamatsu H5784-04 PMT was stored inside of a box during data acquisition in order to minimize background light interference and viewed the combustor through a Newport spectral filter to reject emission that was not associated with the $\mathrm{OH}^{*}$ radical. It had a center frequency of $310 \mathrm{~nm}$ and a half width of $10 \mathrm{~nm}$. As shown in Figure 5, it was situated $546 \mathrm{~mm}$ from the combustor window, where it could view the entire width of the flame.

These PMT time series data were acquired 10 times for each fuel and air inlet temperature, resulting in 200 total cases that were analyzed. Data was also taken at $550 \mathrm{~K}$ but there were nonnegligible acoustic oscillation levels ( $\mathrm{p}^{\prime} / \mathrm{P} \sim 0.7 \%$, as opposed to $0.25 \%$ at $300 \mathrm{~K}$ and $450 \mathrm{~K}$ ). Given the potential influence of thermoacoustic coupling on blowoff, results are only shown for the $300 \mathrm{~K}$ and $450 \mathrm{~K}$ data.

\subsection{High Speed $\mathrm{CH}^{*}$ Chemiluminescence Videos}

$\mathrm{CH}^{*}$ chemiluminescence videos were taken as the blowoff process occurred. The images were acquired at $4 \mathrm{kHz}$ with a 12 bit Photron SA5 camera. Each recorded video captured between 2,000-3,000 images. The camera resolution was set to $1024 \times 1024$ pixels, which resulted in a final resolution of approximately $97 \mu \mathrm{m} /$ pixel. An AT-X M100 Tokina lens with $\mathrm{f}=100 \mathrm{~mm}$ and a f/D=2.8 setting was used with the camera. A $434 \mathrm{~nm}$ centered spectral filter with a $17 \mathrm{~nm}$ bandwidth was used to capture the emission from the $\mathrm{CH}^{*}$ radical.

In order to record a blowoff process, a photomultiplier tube (PMT) signal was used to activate the high-speed camera. Using the falling edge from a PMT signal following a blowoff event, a timing box was used to trigger the camera. A $50 \mu$ s delay was set on the timing box in order to ensure that the flame had fully extinguished before the camera began recording. The camera was back triggered, such that it retained the images that were stored in its buffer during the viewing window preceding the receipt of the PMT signal's indication of blowoff. This procedure was repeated 2-8 times for each of the four fuels at the two different air inlet temperatures. Both the chemiluminescence videos and the PMT measurements were recorded during the blowout transient $\left(\phi-\phi_{L B O} \rightarrow 0\right)$. Table 2 summarizes the conditions where these data were acquired. 
Table 2: Conditions where PMT measurements $(\mathrm{A}, \mathrm{B})$ and $\mathrm{CH}^{*}$ chemiluminescence videos $(\mathrm{C}$, D) were taken.

\begin{tabular}{|c|c|c|c|c|}
\hline Condition & Equivalence Ratio & Temperature (K) & Fuels & Recording Time \\
\hline A & $0.1>\phi-\phi_{L B O} \rightarrow 0$ & 450 & All fuels in Table 1 & 50 seconds \\
\hline B & $0.1>\phi-\phi_{L B O} \rightarrow 0$ & 300 & All fuels in Table 1 & 50 seconds \\
\hline C & $\phi-\phi_{L B O} \rightarrow 0$ & 450 & A-2, C-1, n-Dodecane, S2 & Less than 1 sec \\
\hline D & $\phi-\phi_{L B O} \rightarrow 0$ & 300 & A-2, C-5, n-Dodecane, S2 & Less than 1 sec \\
\hline
\end{tabular}

\section{Analysis}

\subsection{Event Detection from $\mathrm{OH}^{*} \mathrm{PMT}$ Time Series}

Spatially integrated measurements of filtered flame luminosity are a useful way to characterize the blowout process of a flame throughout its entire history, from stable burning to complete blowoff. The same double threshold method described by Murganandam [44] was used here to identify LBO precursor events from PMT measurements. The thresholds are calculated as a fixed percentage of the moving average of the mean. The signal must descend below and recover above both thresholds in order for a drop in intensity to be classified as an "event". The threshold values for both air temperatures were selected according to the general thresholding criteria suggested by Nair and Lieuwen [61], and the overall trends presented later are not a strong function of these specific values.

The upper threshold was $55 \%$ of the local mean and the lower threshold was $40 \%$ of the local mean for the $450 \mathrm{~K}$ data. The upper threshold was $65 \%$ of the local mean and the lower threshold was $50 \%$ of the local mean for the $300 \mathrm{~K}$ data. Lower threshold values were used at $450 \mathrm{~K}$ than $300 \mathrm{~K}$ because the $450 \mathrm{~K}$ flames blew out at lower equivalence ratios. The $450 \mathrm{~K}$ flames could also sustain more frequent extinction processes before their stability was significantly threatened.

Figure 6 shows an example of the PMT time series and double thresholds for fuel A-2 operating at both air inlet temperatures. It is apparent that the number of threshold crossings increases near blowout. The contrast in event frequency and duration between stable operation and lean blowout, averaged across the 10 cases for each fuel, is shown in Figure 7. The equivalence ratio was measured in 1 second intervals as LBO was approached and the number of events in each of these intervals was counted. Similarly, the average duration of the events in each interval was determined. Since the event count for each individual run did not always increase smoothly from zero to the blowoff value, cumulative distribution functions (CDFs) were 
used to define the equivalence ratio at which the events began, $\left(\phi_{\text {event }}\right)$, when there was $10 \%$ probability that an extinction event would cause LBO. This is not meant to imply that local extinction doesn't occur occasionally at equivalence ratios greater than $\phi_{\text {event }}$ when the flame is very stable. Rather, $\phi_{\text {event }}$ serves as a boundary for significant increases in the number and intensity of local extinction processes.

The following information was extracted from the PMT data - the average duration of the events, $\tau_{\text {event }}$, the equivalence ratio at which the events began $\left(\phi_{\text {event }}\right)$, and the percentage of burning time in the near blowoff stages $\left(\phi_{\text {event }}>\phi>\phi_{L B O}\right)$ that was constituted by extinction, $\% \tau_{\text {ext }}$. These values were determined for each individual run and then averaged over the 10 cases for each fuel. The error bars that are shown in the plots in sections 5.1-5.2 represent a combined uncertainty with two contributions. One is a thresholding contribution that comes from the difference between the values at the selected thresholds and those at $\pm 5 \%$ of the chosen thresholds. The other is a data variability contribution that was determined using $95 \%$ confidence intervals. Although the quantitative values (e.g., $\% \tau_{e x t}$ ) do depend on the threshold that was used, the general trends in each of the following plots were very insensitive to the threshold value.

\subsection{Flame Leading Edge Location and Velocity}

Videos were used to understand the spatio-temporal flame dynamics preceding complete blowout. Far from blowoff, the flame stabilized in a consistent spatial location. Figure 8 shows an instantaneous image of a stable flame burning at $\phi=0.41$ (left). As the equivalence ratio was reduced towards the lean blowout limit, stable burning was interrupted by what appear to be extinction and re-ignition events. Two examples at $\phi=0.34$ are shown in the center and right images of the same figure. Local extinction is evident in these images, but there is not an immediate risk that these flames will blow out; i.e., they are in "stage 1". Following the terminology of Muruganandam [44], these temporary extinction processes will be referred to as "LBO precursor events". Planar measurements of these flames have also been acquired and are presented in the author's thesis [62]. They show that burning occurs in both the inner and outer recirculation zones far from blowoff. The outer flame weakens and eventually nearly disappears as LBO is approached, until only the inner flame remains just before LBO. 
Near blowoff, the most upstream point of the flame jumps axially back and forth, presumably associated with extinction, re-ignition, and axial convection. Two separate examples of this phenomenon, each including an LBO precursor event, are shown in Figure 9 and Figure 10. An analysis of the most upstream spatial location where luminosity was detected $\left(x_{u p}\right)$ was used to characterize these LBO precursors. Flame edge tracking techniques were used to identify $x_{u p}$ in each image. This location was determined in the following manner. First, the images were inverted in order to accentuate the flame edge. This procedure enhanced the contrast between the image background and the image area occupied by the flame. Image denoising techniques were then used in order to further sharpen the flame edge. Much of the noise was periodic due to the dim edges of these weakly burning flames being near the detection limit of the camera. Therefore, an automated filtering process developed by Sur and Grediac [63], that operated in the image frequency domain, was used to remove this periodic noise from the images. A Gaussian smoothing filter with a standard deviation of four was then applied to the images in order to prevent random noise from being picked up by the edge detection algorithm. A global threshold, determined by Otsu's method [64], was then used to define the flame edge for each image.

Using this axial coordinate, $x_{u p}$, and the time interval between images, the distance that the flame travels between images, $\Delta x_{u p}$, can be converted to a velocity, $v_{u p}$. Positive velocities represent the flame either being convected downstream or extinguishing. Comparison of these flame velocities with flow velocities provides some insight into which $\Delta x_{u p}$ distances may be associated with extinction and ignition. Two measured axial flow velocity PDFs are shown in Figure 11, obtained from reacting stereo-PIV measurements [25, 65]. Both the axial flow velocity PDF based on the total measurement domain, $U_{\text {Total }}$, and the PDF of the axial velocities in the central recirculation zone (i.e., all spatial locations in the CRZ where the velocity is negative), $U_{C R Z}$, are shown. These data indicate that the peak positive flow velocity is approximately $52 \mathrm{~m} / \mathrm{s}$ (see Figure 11). Any forward motion of the leading luminosity point at a velocity greater than this value is interpreted as extinction.

Negative velocities represent either flame propagation, reverse flow, or re-ignition processes. Turbulent flame propagation speeds are $\mathrm{O}(1-10 \mathrm{~m} / \mathrm{s})$. The axial flow velocity measurements shown in Figure 11 indicate that the peak reverse flow velocity is around $-30 \mathrm{~m} / \mathrm{s}$ [25, 65]. This implies that $v_{u p}<\sim-30 \mathrm{~m} / \mathrm{s}$ are potentially caused by re-ignition. However, $v_{u p}<\sim-30 \mathrm{~m} / \mathrm{s}$ can also be caused by portions of the flame appearing that were previously undetected. Therefore, 
instances where $v_{u p}<\sim-30 \mathrm{~m} / \mathrm{s}$ had to also coincide with an LBO precursor event in order for them to be considered a re-ignition occurrence. The LBO precursor events in these $\mathrm{CH}^{*}$ chemiluminescence videos were identified by integrating the intensity in each image and applying the same double threshold method discussed previously in reference to the PMT measurements. Each of these integrated time series were standardized before the thresholds were applied to correct for intensity differences in the detected $\mathrm{CH}^{*}$ emission between fuels. The images shown in Figure 9 and Figure 10 constitute an example of re-ignition. Both occurred during an LBO precursor event and the velocity of the leading edge is too great for reverse flow convection or flame propagation. Among the identified re-ignition instances, there were $v_{u p}$ values that ranged between $\sim-30 \mathrm{~m} / \mathrm{s}$ to $\sim-100 \mathrm{~m} / \mathrm{s}$.

A word on nomenclature - we use the word "re-ignition", not "autoignition", in order to reserve the latter expression for low-temperature chemistry driven chemical induction processes. In contrast, there are multiple physical processes involved in the re-ignition of a locally extinguished flame, including mixing, edge flame propagation, independently burning flame parcels, autoignition, and the contact of reactants with hot combustion products [49, 66-69].

Figure 11 plots the average $450 \mathrm{~K}$ PDFs of $v_{u p}$ taken at condition C. Fuels A-2 and C-1 are

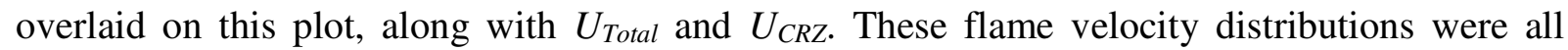
centered at or near $0 \mathrm{~m} / \mathrm{s}$, as must be the case for a flame that is neither completely blowing off nor flashing back. Moreover, the shape of the distributions is largely insensitive to fuel type and blowout equivalence ratio. The shape of the $300 \mathrm{~K}$ distributions are comparable to the $450 \mathrm{~K}$ cases, but the negative $v_{u p}$ values are larger (i.e., the PDFs are narrower). The results for all fuels, including each of the individual runs at both temperatures, are presented in the author's thesis [62].

\section{Results}

This section presents results for the pre-LBO flame dynamics, such as when "events" are first observed or the fraction of time over which they occur, as a function of fuel composition.

\subsection{Onset of "events"}

Prior work has extensively correlated the conditions under which LBO occurs with kinetic and fluid mechanic parameters. As noted in the Introduction, it has been hypothesized that these 
correlations likely capture the physics associated with the extinction processes that happen near blowoff, and not blowoff itself [6]. If this hypothesis is correct, it should be expected that the same correlations that work for $\phi_{L B O}$ should also work for $\phi_{\text {event }}$.

Figure 12 shows the LBO boundaries of the cases where the $\mathrm{OH}^{*}$ time series were acquired, similar to the previously published results [25] shown in Figure 1, plotted against $\phi_{\text {event }}$. For reference a 1-1 line is dropped in, indicating the limit where $\phi_{\text {event }}=\phi_{L B O}$. The difference between these two equivalence ratios, $\phi_{\text {event }}-\phi_{L B O}$, quantifies the key observations summarized in the Introduction - that blowoff is preceded by extinction- and quantifies the separation in $\phi$ space between when they occur. It is also important from an operational standpoint because it indicates how close a combustor can safely approach LBO with some warning that it is imminent.

It can be seen that $\phi_{\text {event }}$ has a nearly linear relationship to $\phi_{L B O}$ and the $\phi_{\text {event }}=\phi_{L B O}$ line at $300 \mathrm{~K}$. The slope of the line at $450 \mathrm{~K}$ is slightly different, suggesting some systematic difference between $\phi_{\text {event }}$ and $\phi_{L B O}$. Further insight into these points can be gained from Figure 13, which plots the dependence of $\phi_{\text {event }}-\phi_{L B O}$ upon the DCN. Figure 13 shows that at $450 \mathrm{~K},\left(\phi_{\text {event }}-\phi_{L B O}\right)$ increases for high DCN fuels, although fuel C-9 is an exception and the measurement uncertainty is comparable to the spread in the values between fuels. No clear correlation between $\left(\phi_{\text {event }}\right.$ $\left.\phi_{L B O}\right)$ and $\mathrm{T}_{90}$ exists at $300 \mathrm{~K}$. These results share similarities with the re-ignition measurements at conditions $\mathrm{C}$ and D, which are presented in Figure 20, and will be revisited in section 5.3.

Note that the mean $\phi_{L B O}$ values shown in Figure 12 and Figure 13 are close to those shown in Figure 1, but do not exactly match. This difference is due to the significantly larger number of LBO measurements (greater than 60 data points per fuel, repeated over three days) taken for the earlier study [25], whose focus was careful determination of fuel effects on $\phi_{L B O}$ values. The results shown in Figure 12 and Figure 13 are averaged from the smaller number of repetitions used for this study (ten times for each fuel), which focuses on the entire process before, up to, and finally culminating in blowoff.

An important question raised in the introduction is the degree to which $\left(\phi_{\text {event }}-\phi_{L B O}\right)$ changes with fuel composition and operating condition. These results suggest that there is some effect but it is weak and only evident at $450 \mathrm{~K}$. The fact that $\phi_{L B O}$ and $\phi_{\text {event }}$ have the same behaviors 
lends further support to the hypothesis outlined in the beginning of this section - that correlations for LBO describe the physics associated with the onset of extinction and re-ignition, "stage 1".

\subsection{Extinction Behaviors under near LBO Conditions}

This section analyzes extinction behaviors under conditions near LBO, including the effect of fuel composition. Interestingly, we observed no instances of flame motion downstream at velocities faster than the flow (see Figure 11); this indicates that the flame does not actually extinguish in some large region of space, so that the leading edge of the reaction volume jumps discontinuously downstream. Rather, "extinction events" are actually "downstream convection events". It is likely that a small region of the flame responsible for flame stabilization extinguishes, leading to downstream convection of the flame. In contrast, data clearly indicates the presence of the leading edge of the flame traveling upstream at velocities significantly higher than would be associated with convection or flame propagation, as discussed in the next section.

We next consider the duration of extinction events, and the extinction history of these flames in the near-blowoff stages, $\phi_{\text {event }}>\phi>\phi_{L B O}$. The extinction history was quantified as the percentage of time when the flame was in an extinguished condition $\left(\% \tau_{e x t}\right)$. Figure 14 shows the average duration of extinction events, $\tau_{\text {event }}$, plotted against $\mathrm{T}_{50}$ on the left and $\mathrm{T}_{90}$ on the right, at $300 \mathrm{~K} . \tau_{\text {event }}$ ranges in value from about $2-6 \mathrm{~ms}$ at $300 \mathrm{~K}$, and the plot on the left in Figure 16 shows that it ranges from $1-2 \mathrm{~ms}$ at $450 \mathrm{~K}$. In other words, the extinction event time interval at $450 \mathrm{~K}$ is less than half than at $300 \mathrm{~K}$. For reference, a bulk fluid mechanic time scale associated with the nozzle exit diameter and velocity, $D / U$, is $\sim \mathrm{O}(0.1 \mathrm{~ms}) . \% \tau_{\text {ext }}$ at $300 \mathrm{~K}$ is plotted in Figure 15 as a function of $\mathrm{T}_{50}$ (left) and $\mathrm{T}_{90}$ (right) and the right plot in Figure 16 shows $\% \tau_{\text {ext }}$ at $450 \mathrm{~K}$. In both cases, the extinction events persist for about $0.8-1.3 \%$ of the time.

At $300 \mathrm{~K}$, there is a clear correlation of $\tau_{\text {event }}$ with $\mathrm{T}_{50}$ (there is also a strong correlation with $\mathrm{T}_{90}$, but the correlation is strongest with $\mathrm{T}_{50}$ ). Specifically, fuels that vaporized most easily have the shortest events and the fuels that were most difficult to vaporize had the longest events. Similarly, the fraction of time, $\% \tau_{e x t}$, is also correlated with $\mathrm{T}_{90}$ at $300 \mathrm{~K}$. The flames of difficult to vaporize fuels remain in an extinguished condition for a greater amount of time before they blow out than easily vaporized fuels.

Much weaker correlations are seen at $450 \mathrm{~K}$. $\tau_{\text {event }}$ perhaps depends on $\mathrm{T}_{90}$ somewhat but the differences between fuels are minor. $\% \tau_{e x t}$ is also very similar between fuels and showed no 
correlation with the DCN, even though $\phi_{L B O}$ is highly correlated with the DCN at $450 \mathrm{~K}$. It is possible that $\mathrm{C}-1$, the high TSI fuel, and n-dodecane experiencing slightly more extinction time than the other fuels, but these deviations are well within the uncertainty.

It is also of interest to note the similarity in ranges of the $\% \tau_{\text {ext }}$ value observed at both $300 \mathrm{~K}$ and $450 \mathrm{~K}$, and across the fuels, all lying in the approximate $0.8-1.3 \%$ range. There is no reason to expect that these percentages should be similar, given that $\phi_{L B O}$ occurs at substantially higher values at $300 \mathrm{~K}$ than $450 \mathrm{~K}$, and that the length of extinction events is quite different as well. However, this observation provides some clues to the relationship between $\phi_{\text {event }}$ and $\phi_{L B O}$. As noted in Shanbhogue et al.'s review [6], it is clear that flames can withstand a certain fraction of extinction but still exist indefinitely without blowing off. However, it is also clear that the flame will blow off if the fraction of time and/or space that extinction occurs is too large (this was referred to as the "critical extinction level" in Shanbogue's review). This is likely due to a reduction in temperature of the hot recirculating gases responsible for re-igniting the oncoming mixture. What this "critical extinction value" should be is not currently understood. However, if this "critical extinction value" hypothesis is correct, then one would expect more universal behavior across operating conditions and fuel compositions right near blowoff. The fact that $\% \tau_{\text {ext }}$ has nearly the same value across all the fuels, and at both temperatures, is consistent with this idea.

However, the above results are essentially an average over the range, $\phi_{\text {event }}>\phi>\phi_{L B O}$. In order to further evaluate the above "critical extinction value" hypothesis, these values were recalculated over a much narrower range of $\phi$ values right on the edge of blowoff. This procedure reduces some of the averaging that is present over a broader range of equivalence ratios, but also increases the random error in the extinction event statistics, as there are fewer realizations to average over. Figure 17, Figure 18, and Figure 19 plot $\tau_{\text {event }}$ and $\% \tau_{\text {ext }}$ right on the edge of blowoff, $\phi_{L B O+\varepsilon}>\phi>\phi_{L B O}$, where $\varepsilon \sim 0.002$ (calculated by taking the final second of data before LBO). These figures show that even on the very edge of blowoff extinction events are uncommon. The maximum value in $\% \tau_{\text {ext }}$ is always less than $10 \%$, with values closer to $3-5 \%$ for most cases. Comparing these results with those in Figure 14, Figure 15, and Figure 16, note that the trends in $\tau_{\text {event }}$ do not change qualitatively, although there is somewhat of an increase in $\tau_{\text {event }}$ relative to its value when averaged over $\phi_{\text {event }}>\phi>\phi_{L B O}$. Similar conclusions apply for 
$\% \tau_{e x t}$ at $450 \mathrm{~K}$. However, the picture does change for $\% \tau_{e x t}$ at $300 \mathrm{~K}$; here we see that its value is now appreciably higher than at $450 \mathrm{~K}$ and does also seem to increase with $\mathrm{T}_{50}$ and $\mathrm{T}_{90}$. Taken together, these results suggest that the "critical extinction value" hypothesis is a helpful but incomplete characterization of why flames ultimately transition from local extinction to complete blowoff.

\subsection{Re-ignition Behaviors Under Near LBO Conditions}

This section analyzes the re-ignition behaviors under conditions near LBO, including the effect of fuel composition. As noted earlier, the data clearly indicates the presence of the leading edge of the flame traveling upstream at velocities significantly higher than would be associated with convection or flame propagation. These realizations in the negative velocity tails of the $v_{u p}$ PDFs, that also satisfied the LBO precursor event criterion, were used as an indicator of the near blowoff re-ignition propensity of these fuels. Of course, these values must be referenced against the number of extinction events that the flame must recover from. Therefore, the number of reignition instances in each run was normalized by the corresponding number of extinction events.

Figure 20 plots the percentage of extinction events where $v_{u p}<-30 \mathrm{~m} / \mathrm{s}$, averaged across each of the cases for a given fuel, at conditions C (left) and D (right). This percentage of $v_{u p}$ is plotted against the $\mathrm{DCN}$ and $\mathrm{T}_{90}$, the fuel properties previously shown to correlate best with LBO at 450 $\mathrm{K}$ and $300 \mathrm{~K}$, respectively (see Figure 1) [25]. First, note that while re-ignition does occur after an extinction event, it is relatively infrequent, occurring in most cases about 20-30\% of the time. The peak value is $50 \%$ for $\mathrm{n}$-dodecane at $450 \mathrm{~K}$, and is only observed for fuel $\mathrm{S} 2$ at $300 \mathrm{~K}$. This indicates that, with the exception of n-dodecane at $450 \mathrm{~K}$, the flame recovers from the majority of extinction events through some other means than re-ignition - presumably simply upstream convection and propagation of the flame.

Consider next the fuel composition sensitivity. It can be seen that high DCN fuels have a much greater propensity for re-ignition recoveries at $450 \mathrm{~K}$ than low DCN fuels. As each of these fuels experiences approximately the same amount of extinction at $450 \mathrm{~K}$ (see Figure 19), this is a likely explanation for the positive correlation between $\left(\phi_{\text {event }}-\phi_{L B O}\right)$ and the DCN shown in Figure 13. Once the flame begins experiencing LBO precursor events, the operation of high DCN fuels is extended to lower equivalence ratios because these fuels are better able to recover through re-ignition. The superior LBO performance of high DCN fuels should not be limited to 
strictly re-ignition considerations, as Figure 12 shows that these fuels also have lower $\phi_{\text {event }}$ values. Therefore, it appears that high DCN fuels are better able to resist blowoff by delaying the onset of LBO precursor events, and then their improved re-ignition performance allows them to survive longer once these precursor events begin to threaten the stability of the flame.

Given that LBO is predominantly vaporization limited at $300 \mathrm{~K}$, fuel composition effects were not expected to be found in the re-ignition characteristics. The $\% v_{u p}<-30 \mathrm{~m} / \mathrm{s}$ values shown on the right in Figure 20 indicate that re-ignition recoveries only occurred for the highest $\mathrm{T}_{90}$ fuel, S2. This is likely related to the greater susceptibility of this fuel for extinction, as was discussed previously. Furthermore, the re-ignition instances that did occur for S2 at $300 \mathrm{~K}$ happened infrequently. As noted above, the flame recovers from the majority of extinction events through some other means than re-ignition - presumably simply upstream convection and propagation of the flame.

\section{Conclusion}

This paper describes the detailed dynamics that precede the blowout of spray flames, and how these dynamics are influenced by ambient conditions and fuel properties. These data clearly show extinction, re-ignition, and recovery of the flame ("events") as blowoff is approached, analogous to prior results on premixed flames. These events grow in frequency and duration as blowoff is approached, with various features that depend upon fuel composition and temperature. Results show that after a near-blowoff event, the flame can move upstream at velocities much faster than the flow velocity, corresponding to re-ignition. In contrast, downstream motion of the flame faster than the flow, which would correspond to bulk flame extinction, was never observed. This indicates that "extinction events" actually correspond to flame convection downstream when it loses its stabilization point. Nonetheless, the majority of the flame recovery events appear to be associated with convection of hot products back upstream, not re-ignition.

Clear physical differences were observed in the $300 \mathrm{~K}$ and $450 \mathrm{~K}$ near-blowoff dynamics. Fuel composition seems to have a lesser effect on the $450 \mathrm{~K}$ extinction behavior, as quantified by $\tau_{\text {event }}$, and $\% \tau_{\text {ext }}$. The amount of time that the flame spends in an extinguished condition was insensitive to fuel type. There was, however, evidence of a higher percentage of re-ignition recoveries for high DCN fuels. This finding, taken in conjunction with the lower $\phi_{\text {event }}$ values for high DCN fuels, suggests that high DCN fuels more successfully resist blowoff by delaying the 
onset of LBO precursor events and then they are more often able to recover from these precursor events through re-ignition. The $300 \mathrm{~K}$ PMT analysis showed that there is a strong correlation between a fuel's boiling point temperature and the duration of its extinction history preceding LBO. Furthermore, high boiling point temperature fuels were also found to be much more likely to experience re-ignition recoveries. A possible phenomenological explanation is that the longer extinction durations are a manifestation of the flame cooling as high boiling point temperature droplets slowly vaporize. Without gaseous fuel to burn, hot gases will be swept downstream and the flame is more often required to re-ignite in order to reestablish a stable flame.

\section{Acknowledgement}

This work was partially supported by AFOSR (contract \#FA9550-16-1-0442), contract monitor Dr. Chiping Li, and ASCENT, the FAA Center of Excellence for Alternative Jet Fuels and the Environment (Award \#13-C-AJFE-GIT-008) under the supervision of Cecilia Shaw. Any opinions, findings, conclusions or recommendations expressed in this material are those of the authors and do not necessarily reflect the views of the FAA. The authors also gratefully acknowledge the ideas and insight of numerous colleagues, including Randal McKinney, Jeff Cohen, Jeff Lovett, Med Colket, Tim Edwards, and Joshua Heyne.

\section{References}

[1] M. Colket, J. Heyne, M. Rumizen, M. Gupta, T. Edwards, W.M. Roquemore, G. Andac, R. Boehm, J. Lovett, R. Williams, Overview of the national jet fuels combustion program, AIAA Journal 55 (2017) 1-18.

[2] E.E. Zukoski, Flame stabilization on bluff bodies at low and intermediate Reynolds numbers, California Institute of Technology, 1954.

[3] E.E. Zukoski, F.E. Marble, Experiments concerning the mechanism of flame blowoff from bluff bodies, California Institute of Technology, 1983.

[4] J.P. Longwell, E.E. Frost, M.A. Weiss, Flame Stability in Bluff Body Recirculation Zones, Industrial and Engineering Chemistry 45 (1953) 1629-1633.

[5] Q. Zhang, S.J. Shanbhogue, T. Lieuwen, Dynamics of premixed $\mathrm{H} 2 / \mathrm{CH} 4$ flames under near blowoff conditions, Journal of Engineering for Gas Turbines and Power 132 (2010) 111502.

[6] S.J. Shanbhogue, S. Husain, T. Lieuwen, Lean blowoff of bluff body stabilized flames: Scaling and dynamics, Progress in Energy and Combustion Science 35 (2009) 98-120.

[7] K.M. Lyons, Toward an understanding of the stabilization mechanisms of lifted turbulent jet flames: experiments, Progress in Energy and Combustion Science 33 (2007) 211-231. 
[8] A. Lefebvre, Fuel effects on gas turbine combustion-ignition, stability, and combustion efficiency, Journal of Engineering for Gas Turbines and Power 107 (1985) 24-37.

[9] A. Mellor, Semi-empirical correlations for gas turbine emissions, ignition, and flame stabilization, Progress in Energy and Combustion Science 6 (1980) 347-358.

[10] M. Colket, S. Zeppieri, Z. Dai, D. Hautman, Fuel research at UTRC, Multi-Agency Coordinating Council for Combustion Research 5th Annual Fuel Research Meeting, Livermore, California, 2012.

[11] T. Mosbach, V. Burger, B. Gunasekaran, Fuel composition influence on gas turbine ignition and combustion performance, ASME Turbo Expo 2015: Turbine Technical Conference and Exposition (2015), paper GT2015-43020.

[12] V. Burger, A. Yates, C. Viljoen, Influence of fuel physical properties and reaction rate on threshold heterogeneous gas turbine combustion, ASME Turbo Expo 2012: Turbine Technical Conference and Exposition (2012), paper GT2012-68153.

[13] J. Grohmann, B. Rauch, T. Kathrotia, W. Meier, M. Aigner, Influence of Single-Component Fuels on Gas-Turbine Model Combustor Lean Blowout, Journal of Propulsion and Power 34 (2018) 111.

[14] S. Stouffer, T. Hendershott, J.R. Monfort, J. Diemer, E. Corporan, P. Wrzesinski, A.W. Caswell, Lean Blowout and Ignition Characteristics of Conventional and Surrogate Fuels Measured in a Swirl Stabilized Combustor, 55th AIAA Aerospace Sciences Meeting (2017), paper AIAA 20171954.

[15] N. Rock, I. Chterev, B. Emerson, J. Seitzman, T. Lieuwen, Blowout Sensitivities in a Liquid Fueled Combustor: Fuel Composition and Preheat Temperature Effects, ASME Turbo Expo 2017: Turbomachinery Technical Conference and Exposition (2017), paper GT2017-63305.

[16] J. Peters, Current gas turbine combustion and fuels research and development, Journal of Propulsion and Power 4 (1988).

[17] P.M. Allison, J.A. Sidey, E. Mastorakos. Lean Blowoff Scaling of Swirling, Bluff-Body Stabilized Spray Flames, 56th AIAA Aerospace Sciences Meeting (2018), paper AIAA 2018-1421.

[18] S.H. Won, P.S. Veloo, S. Dooley, J. Santner, F.M. Haas, Y. Ju, F.L. Dryer, Predicting the global combustion behaviors of petroleum-derived and alternative jet fuels by simple fuel property measurements, Fuel 168 (2016) 34-46.

[19] S.H. Won, N. Rock, S.J. Lim, S. Nates, D. Carpenter, B. Emerson, T. Lieuwen, J.T. Edwards, F.L. Dryer, Preferential vaporization impacts on lean blow-out of liquid fueled combustors, Combustion and Flame 205 (2019) 295-304.

[20] S. Dooley, S.H. Won, M. Chaos, J. Heyne, Y. Ju, F.L. Dryer, K. Kumar, C.-J. Sung, H. Wang, M.A. Oehlschlaeger, A jet fuel surrogate formulated by real fuel properties, Combustion and Flame 157 (2010) 2333-2339.

[21] S. Dooley, S.H. Won, J. Heyne, T.I. Farouk, Y. Ju, F.L. Dryer, K. Kumar, X. Hui, C.-J. Sung, H. Wang, The experimental evaluation of a methodology for surrogate fuel formulation to emulate gas phase combustion kinetic phenomena, Combustion and Flame 159 (2012) 1444-1466.

[22] S. Dooley, S.H. Won, S. Jahangirian, Y. Ju, F.L. Dryer, H. Wang, M.A. Oehlschlaeger, The combustion kinetics of a synthetic paraffinic jet aviation fuel and a fundamentally formulated, experimentally validated surrogate fuel, Combustion and Flame 159 (2012) 3014-3020.

[23] D. Kim, J. Martz, A. Violi, A surrogate for emulating the physical and chemical properties of conventional jet fuel, Combustion and Flame 161 (2014) 1489-1498.

[24] W.J. Pitz, C.J. Mueller, Recent progress in the development of diesel surrogate fuels, Progress in Energy and Combustion Science 37 (2011) 330-350.[25] N. Rock, I. Chterev, B. Emerson, S.H. Won, J. Seitzman, T. Lieuwen, Liquid Fuel Property Effects on Lean Blowout in an Aircraft Relevant Combustor, Journal of Engineering for Gas Turbines and Power 141 (2019) 071005. 
[25] N. Rock, I. Chterev, B. Emerson, S.H. Won, J. Seitzman, T. Lieuwen, Liquid Fuel Property Effects on Lean Blowout in an Aircraft Relevant Combustor, Journal of Engineering for Gas Turbines and Power 141 (2019) 071005.

[26] S.H. Won, F.M. Haas, S. Dooley, T. Edwards, F.L. Dryer, Reconstruction of chemical structure of real fuel by surrogate formulation based upon combustion property targets, Combustion and Flame 183 (2017) 39-49.

[27] A. Bokhart, D. Shin, R.M. Gejji, P. Sojka, J.P. Gore, R.P. Lucht, S.V. Naik, T. Buschhagen, Spray Measurements at Elevated Pressures and Temperatures Using Phase Doppler Anemometry, 55th AIAA Aerospace Sciences Meeting (2017), paper AIAA 2017-0828.

[28] A. Bokhart, D. Shin, N.S. Rodrigues, P. Sojka, J.P. Gore, R.P. Lucht, Spray Characteristics of a Hybrid Airblast Pressure-Swirl Atomizer at Near Lean Blowout Conditions using Phase Doppler Anemometry, 56th AIAA Aerospace Sciences Meeting (2018), paper AIAA 2018-2187.

[29] D. Shin, A.J. Bokhart, N.S. Rodrigues, P. Sojka, J.P. Gore, R.P. Lucht, Experimental Study of Spray Characteristics at Cold Start and Elevated Ambient Pressure using Hybrid Airblast Pressure-Swirl Atomizer, 57th AIAA Aerospace Sciences Meeting (2019), paper AIAA 2019-1737.

[30] T. Buschhagen, R.Z. Zhang, A.J. Bokhart, R.M. Gejji, S.V. Naik, R.P. Lucht, J.P. Gore, P.E. Sojka, C.D. Slabaugh, S. Meyer, Effect of Aviation Fuel Type and Fuel Injection Conditions on Nonreacting Spray Characteristics of a Hybrid Airblast Fuel Injector, 54th AIAA Aerospace Sciences Meeting (2016), paper AIAA 2016-1154.

[31] N. Rock, I. Chterev, T. Smith, H. Ek, B. Emerson, D. Noble, J. Seitzman, T. Lieuwen, Reacting Pressurized Spray Combustor Dynamics: Part 1-Fuel Sensitivities and Blowoff Characterization, ASME Turbo Expo 2016: Turbomachinery Technical Conference and Exposition (2016), paper GT2016-56346.

[32] S. Nair, T.C. Lieuwen, Near-blowoff dynamics of a bluff-body stabilized flame, Journal of Propulsion and Power 23 (2007) 421-427.

[33] B.R. Chowdhury, B.M. Cetegen, Effects of free stream flow turbulence on blowoff characteristics of bluff-body stabilized premixed flames, Combustion and Flame 190 (2018) 302-316.

[34] M. Stöhr, I. Boxx, C. Carter, W. Meier, Dynamics of lean blowout of a swirl-stabilized flame in a gas turbine model combustor, Proceedings of the Combustion Institute 33 (2011) 2953-2960.

[35] R. Erickson, M. Soteriou, The influence of reactant temperature on the dynamics of bluff body stabilized premixed flames, Combustion and Flame 158 (2011) 2441-2457.

[36] B. Emerson, J. O'Connor, M. Juniper, T. Lieuwen, Density ratio effects on reacting bluff-body flow field characteristics, Journal of Fluid Mechanics 706 (2012) 219-250.

[37] S. Yamaguchi, N. Ohiwa, T. Hasegawa, Structure and blow-off mechanism of rod-stabilized premixed flame, Combustion and Flame 62 (1985) 31-41.

[38] S. Chaudhuri, S. Kostka, S.G. Tuttle, M.W. Renfro, B.M. Cetegen, Blowoff mechanism of two dimensional bluff-body stabilized turbulent premixed flames in a prototypical combustor, Combustion and Flame 158 (2011) 1358-1371.

[39] C.A. Fugger, B. Paxton, J.R. Gord, B.A. Rankin, A.W. Caswell, Measurements and Analysis of FlowFlame Interactions in Bluff-Body-Stabilized Turbulent Premixed Propane-Air Flames, 57th AIAA Aerospace Sciences Meeting (2019), paper AIAA 2019-0733.

[40] J. Dawson, R. Gordon, J. Kariuki, E. Mastorakos, A. Masri, M. Juddoo, Visualization of blow-off events in bluff-body stabilized turbulent premixed flames, Proceedings of the Combustion Institute 33 (2011) 1559-1566.

[41] J. Pan, D. Ballal. Chemistry and turbulence effects in bluff-body stabilized flames. 30th Aerospace Sciences Meeting and Exhibit (1992), paper AIAA 92-0771. 
[42] E. Hodzic, M. Jangi, R.-Z. Szasz, C. Duwig, M. Geron, J. Early, L. Fuchs, X.-S. Bai, Large Eddy Simulation of Bluff-Body Flame Approaching Blow-Off: A Sensitivity Study, Combustion Science and Technology (2018), https://doi.org/10.1080/00102202.2018.1536125.

[43] J. Kariuki, A. Dowlut, R. Yuan, R. Balachandran, E. Mastorakos, Heat release imaging in turbulent premixed methane-air flames close to blow-off, Proceedings of the Combustion Institute 35 (2015) 1443-1450.

[44] T. Muruganandam, Sensing and dynamics of lean blowout in a swirl dump combustor, Georgia Institute of Technology, 2006.

[45] S. Prakash, Y. Neumeier, B. Zinn. Investigation of Mode Shift Dynamics of Lean, Premixed Flames. in 44th AIAA Aerospace Sciences Meeting and Exhibit. 2006.

[46] Q. Zhang, Lean blowoff characteristics of swirling H2/CO/CH4 Flames. 2008, Georgia Institute of Technology.

[47] I.P. Chterev, Flow Characterization of Lifted Flames in Swirling, Reacting Flows. 2017, Georgia Institute of Technology.

[48] K. Radhakrishnan, J.B. Heywood, R.J. Tabaczynski, Premixed turbulent flame blowoff velocity correlation based on coherent structures in turbulent flows, Combustion and Flame 42 (1981) 19-33.

[49] M. Juddoo, A. Masri, High-speed OH-PLIF imaging of extinction and re-ignition in non-premixed flames with various levels of oxygenation, Combustion and Flame 158 (2011) 902-914.

[50] J. Hult, U. Meier, W. Meier, A. Harvey, C. Kaminski, Experimental analysis of local flame extinction in a turbulent jet diffusion flame by high repetition 2-D laser techniques and multiscalar measurements, Proceedings of the Combustion Institute 30 (2005) 701-709.

[51] A. Steinberg, I. Boxx, C. Arndt, J. Frank, W. Meier, Experimental study of flame-hole reignition mechanisms in a turbulent non-premixed jet flame using sustained multi-kHz PIV and crossedplane OH PLIF, Proceedings of the Combustion Institute 33 (2011) 1663-1672.

[52] R. Yuan, J. Kariuki, A. Dowlut, R. Balachandran, E. Mastorakos, Reaction zone visualisation in swirling spray n-heptane flames, Proceedings of the Combustion Institute 35 (2015) 1649-1656.

[53] M. Evans, J. Sidey, J. Ye, P. Medwell, B. Dally, E. Mastorakos, Temperature and reaction zone imaging in turbulent swirling dual-fuel flames. Proceedings of the Combustion Institute 37 (2019) 2159-2166.

[54] A. Verdier, J.M. Santiago, A. Vandel, G. Godard, G. Cabot, B. Renou, Local extinction mechanisms analysis of spray jet flame using high speed diagnostics, Combustion and Flame 193 (2018) 440452.

[55] R. Yuan, J. Kariuki, E. Mastorakos, Measurements in swirling spray flames at blow-off, International Journal of Spray and Combustion Dynamics 10 (2018) 185-210.

[56] L. Esclapez, P. Ma, M. Ihme, Large-eddy simulation of fuel effect on lean blow-out in gas turbines, Stanford Center for Turbulence Research Annual Research Briefs (2015).

[57] A. Giusti, E. Mastorakos, Detailed chemistry LES/CMC simulation of a swirling ethanol spray flame approaching blow-off, Proceedings of the Combustion Institute 36 (2017) 2625-2632.

[58] J. Cohen, T. Rosfjord, Influences on the Sprays Formed by High-Shear Fuel Nozzle/Swirler Assemblies, Journal of Propulsion and Power 9 (1993) 16-27.

[59] J.T. Edwards, Reference jet fuels for combustion testing, 55th AIAA Aerospace Sciences Meeting (2017), paper AIAA 2017-0146.

[60] F.M. Haas, A. Qin, F.L. Dryer. "Virtual" Smoke Point Determination of Alternative Aviation Kerosenes by Threshold Sooting Index TSI Methods, 50th AIAA/ASME/SAE/ASEE Joint Propulsion Conference (2014), paper AIAA 2014-3468.

[61] S. Nair, T. Lieuwen, Acoustic detection of blowout in premixed flames, Journal of Propulsion and Power 21 (2005) 32-39. 
[62] N.A. Rock, Lean Blowout Sensitivities of Complex Liquid Fuels, Georgia Institute of Technology, 2019.

[63] F. Sur, M. Grediac, Automated removal of quasiperiodic noise using frequency domain statistics, Journal of Electronic Imaging 24 (2015) 1-19.

[64] N. Otsu, A threshold selection method from gray-level histograms, IEEE transactions on systems, man, and cybernetics 9 (1979) 62-66.

[65] I. Chterev, N. Rock, H. Ek, B. Emerson, J. Seitzman, N. Jiang, S. Roy, T. Lee, J. Gord, T. Lieuwen, Simultaneous imaging of fuel, $\mathrm{OH}$, and three component velocity fields in high pressure, liquid fueled, swirl stabilized flames at 5 kHz, Combustion and Flame 186 (2017) 150-165.

[66] U.D. Lee, U., C.S. Yoo, J.H. Chen, J.H. Frank, Effects of $\mathrm{H} 2 \mathrm{O}$ and $\mathrm{NO}$ on extinction and re-ignition of vortex-perturbed hydrogen counterflow flames, Proceedings of the Combustion Institute 32 (2009) 1059-1066.

[67] T.C. Lieuwen, Unsteady combustor physics, Cambridge University Press, 2012.

[68] H. Wang, S.B. Pope, Lagrangian investigation of local extinction, re-ignition and auto-ignition in turbulent flames, Combustion Theory and Modelling 12 (2008) 857-882.

[69] P. Sripakagorn, S. Mitarai, G. Kosály, H. Pitsch, Extinction and reignition in a diffusion flame: a direct numerical simulation study, Journal of Fluid Mechanics 518 (2004) 231-259.
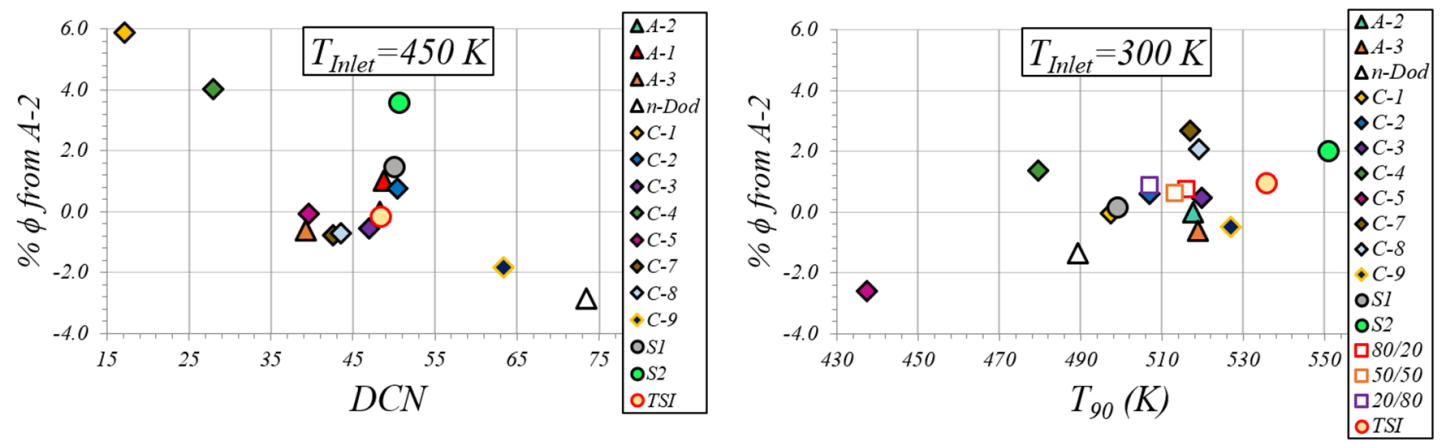

Figure 1: Percent difference in the blowout equivalence ratio from the reference fuel, A-2, taken from [25]. The $450 \mathrm{~K}$ results (left) are plotted against the $\mathrm{DCN}$ and the $300 \mathrm{~K}$ (right) results are plotted against $\mathrm{T}_{\mathbf{9 0}}$.

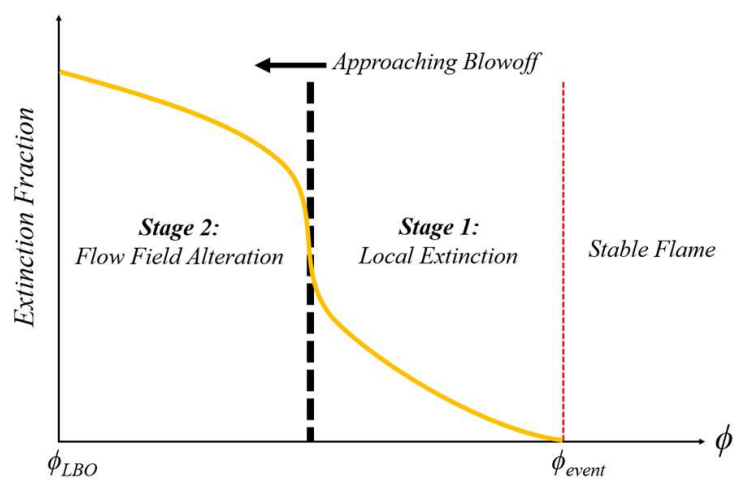

Figure 2: Conceptual illustration of the blowoff process in premixed systems, adapted from [6]. 


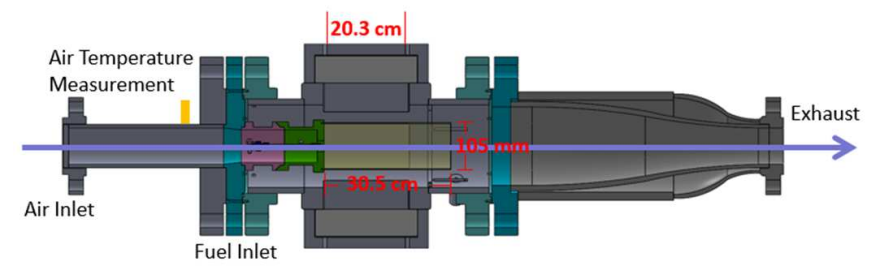

Figure 3: Illustration of the Georgia Tech spray combustor.

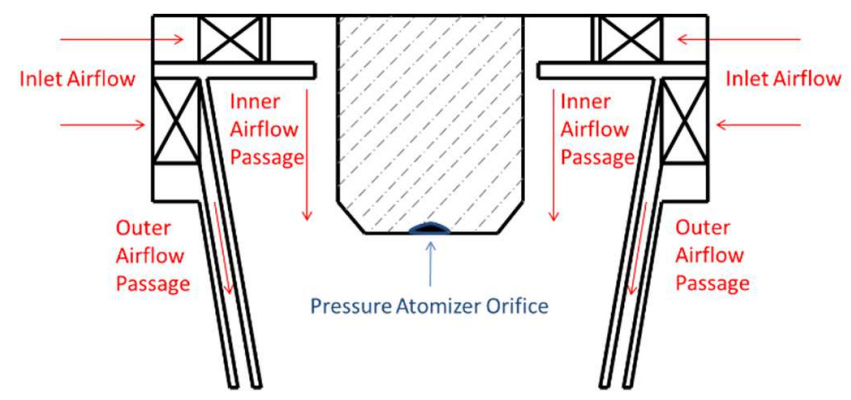

Figure 4: Schematic of the nozzle geometry, including the swirler and fuel injector.

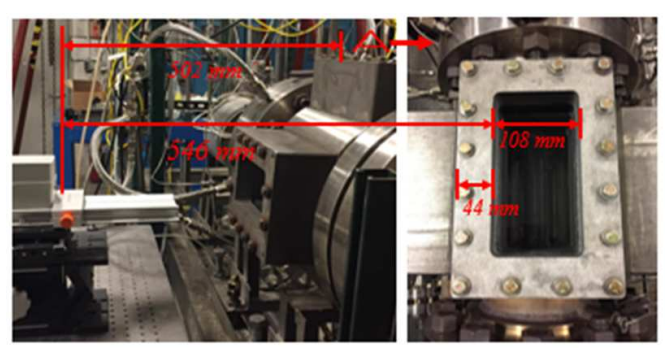

Figure 5: PMT placement and associated distances to the test section. The image on the left is a side view of the combustor and the right image represents a top down view of the combustor.
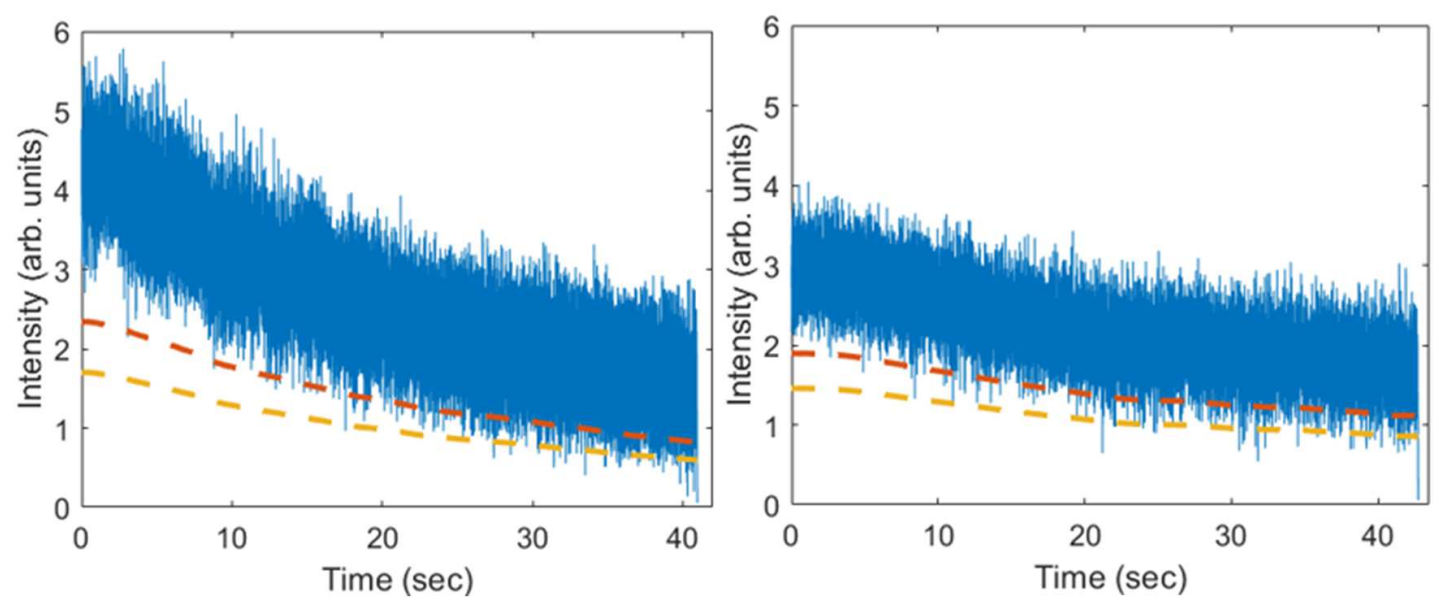

Figure 6: PMT time series at a $450 \mathrm{~K}$ air inlet temperature (left) and a $300 \mathrm{~K}$ air inlet temperature (right). The upper and lower thresholds are represented by the orange and yellow dashed lines, respectively. 


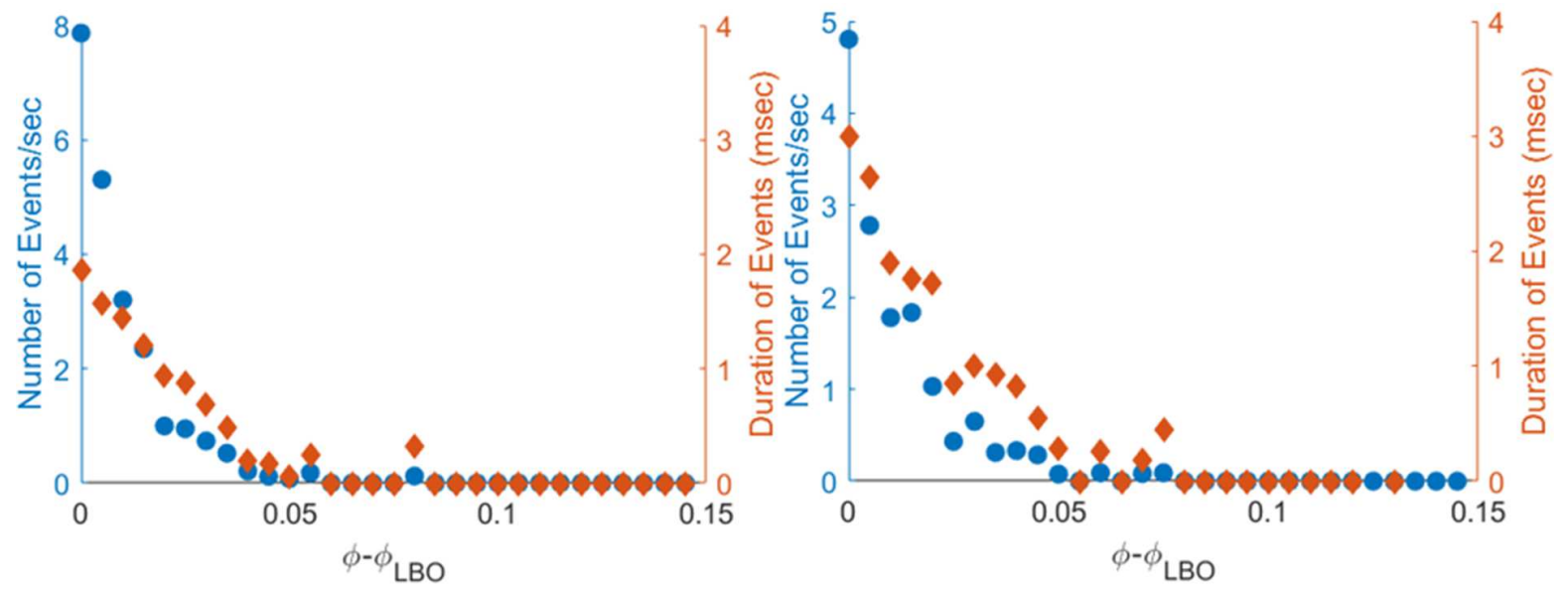

Figure 7: Equivalence ratio dependence of the average event frequency and duration as blowout is approached, at a $450 \mathrm{~K}$ air inlet temperature (left) and $300 \mathrm{~K}$ air inlet temperature (right). The fuel is A-2 (Jet-A) in both instances.

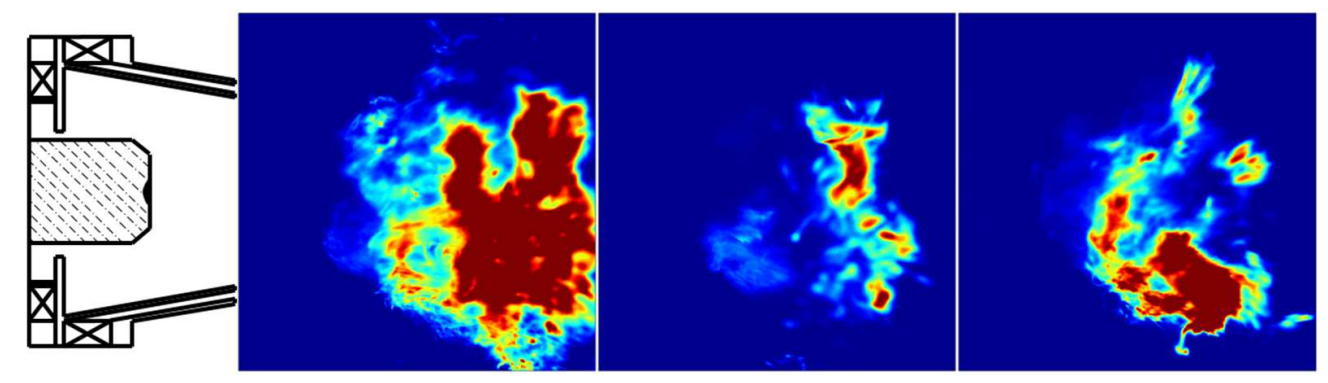

Figure 8: Instantaneous $\mathrm{CH}^{*}$ chemiluminescence images taken of the flame at $\phi=0.41$ (left) and $\phi=0.34$ (center and right). A-2 (Jet-A) is burning in each of these images at $450 \mathrm{~K}$. 


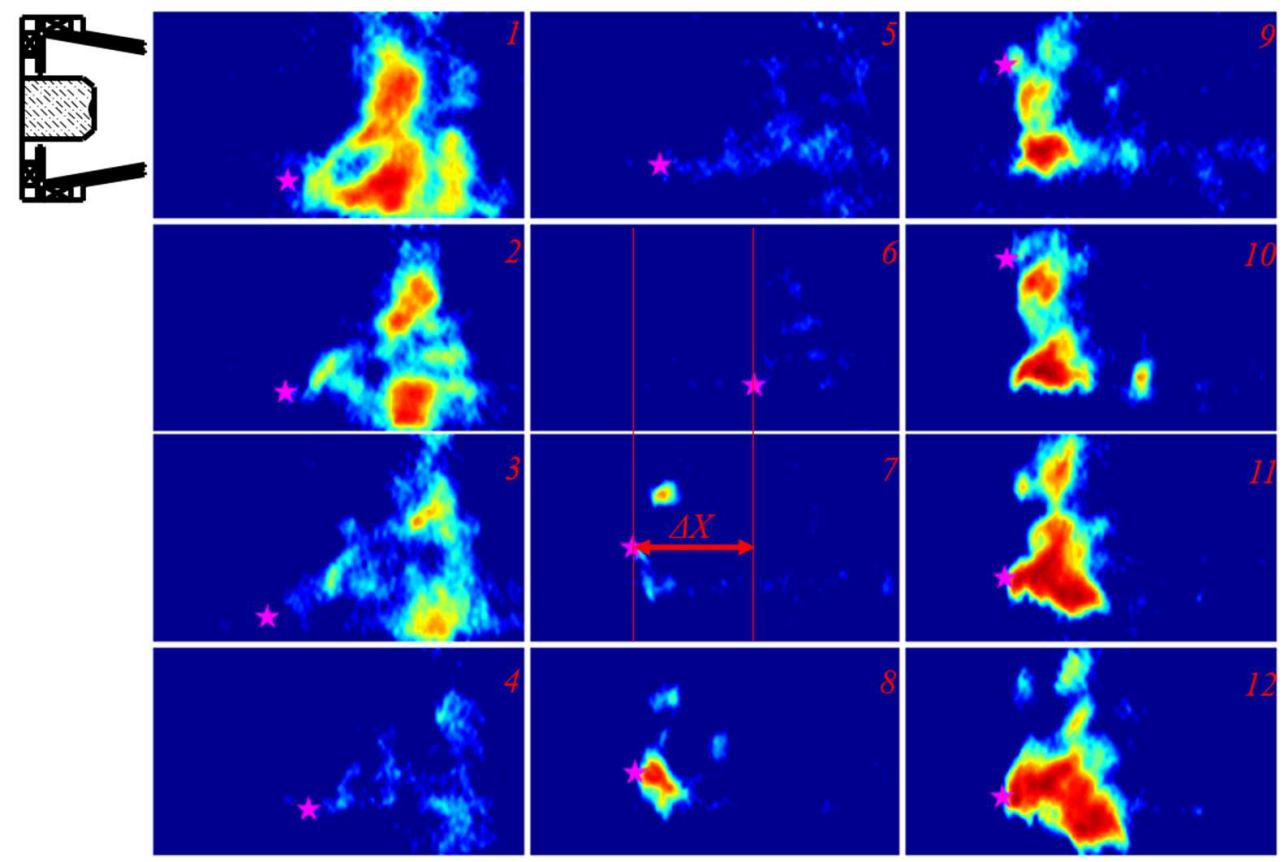

Figure 9: Twelve successive $\mathrm{CH}^{*}$ chemiluminescence images taken during an event at $\phi=0.30$. The star denotes the most upstream spatial location of luminosity. $\mathrm{N}$-dodecane is burning in these images at a $450 \mathrm{~K}$ air inlet temperature.

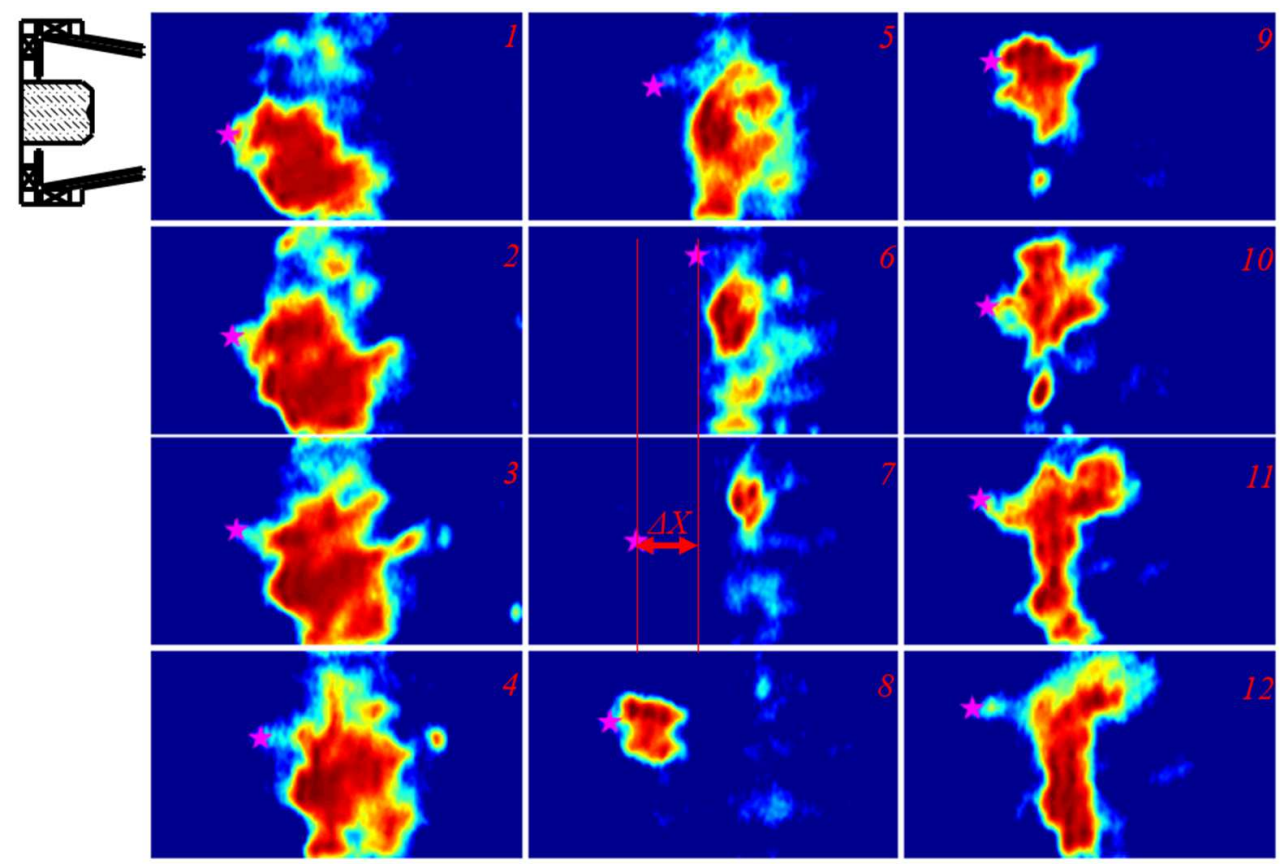

Figure 10: Twelve successive $\mathrm{CH}^{*}$ chemiluminescence images taken during an event at $\phi=0.32$. The star denotes the most upstream spatial location of luminosity. A-2 (Jet-A) is burning in these images at $450 \mathrm{~K}$. 


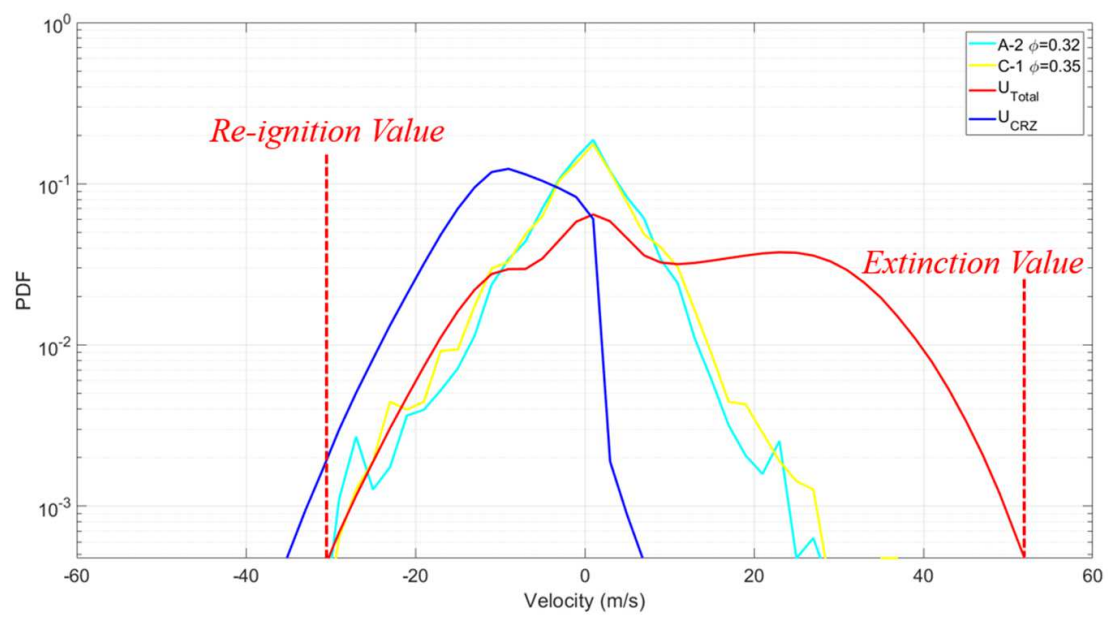

Figure 11: Average $450 \mathrm{~K}$ PDF of $v_{u p}$ at condition C for A-2 and C-1. The axial flow velocity PDFs $U_{\text {Total }}$ and $U_{C R Z}$ are also shown.

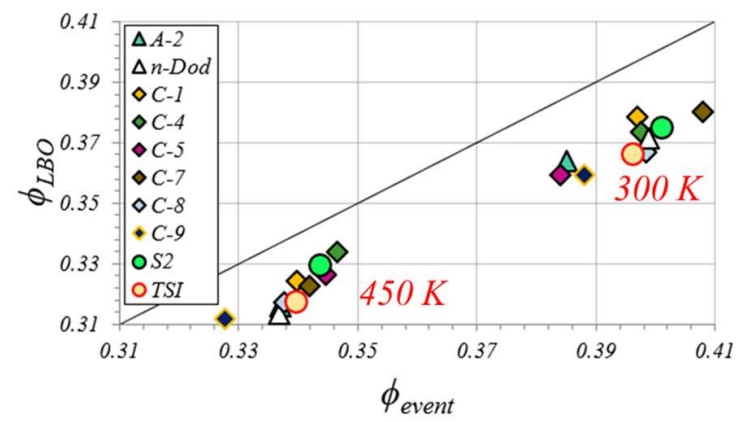

Figure 12: Equivalence ratio at which blowoff occurs, $\phi_{L B O}$, plotted against the equivalence ratio where events initiate, $\phi_{\text {event. }}$ Results are included at both air inlet temperatures.
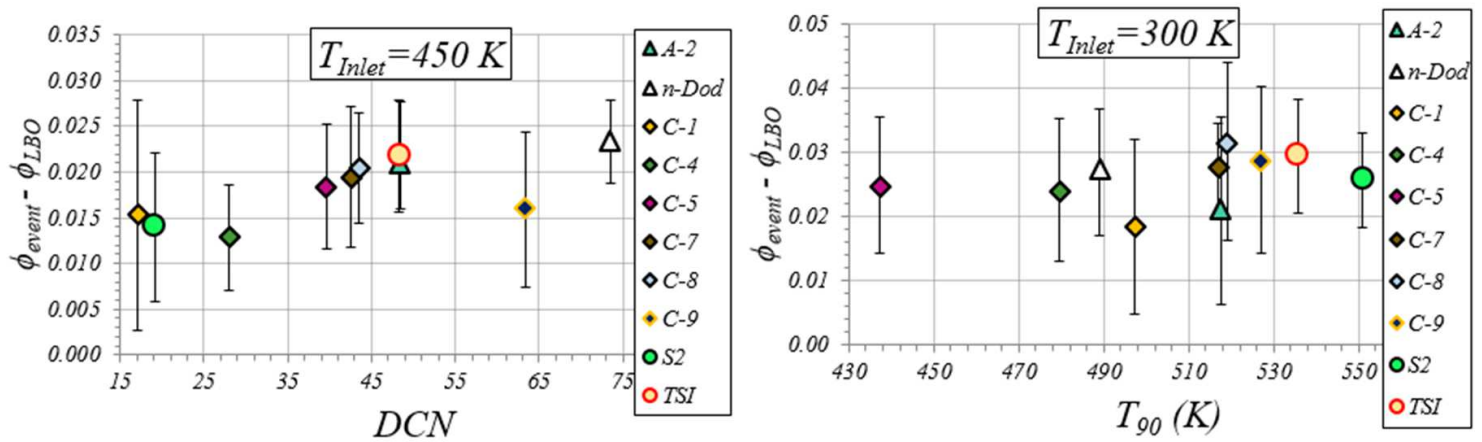

Figure 13: $\left(\phi_{\text {event }}-\phi_{L B O}\right)$ plotted against the DCN at $450 \mathrm{~K}$ (left) and $\mathrm{T}_{90}$ at $300 \mathrm{~K}$ (right). 

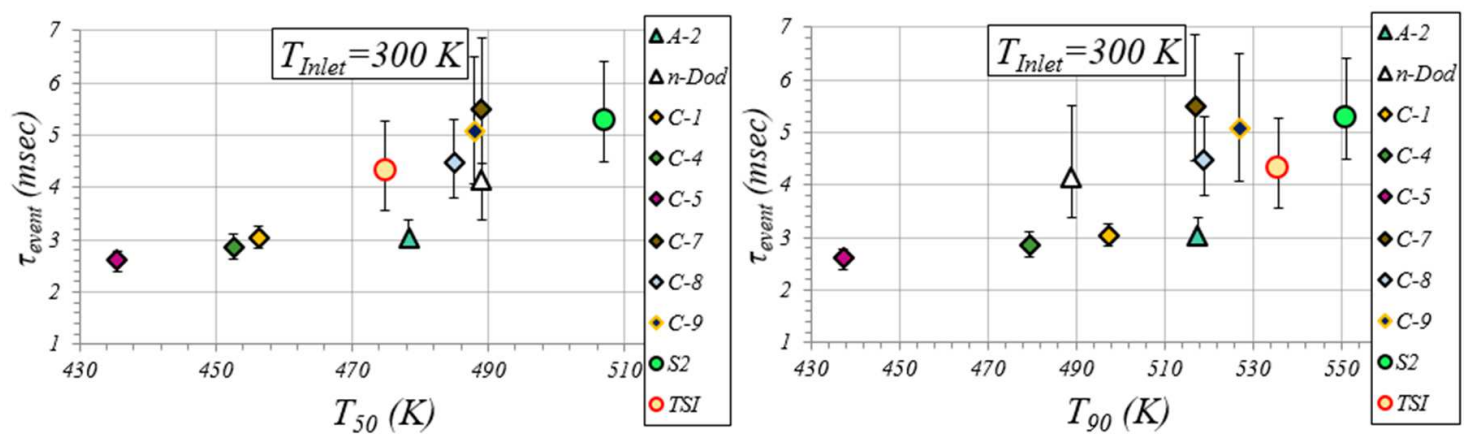

Figure 14: Average duration of the LBO precursor events, $\tau_{\text {event}}$, plotted against $T_{50}$ on the left and $T_{90}$ on the right. (Condition B)
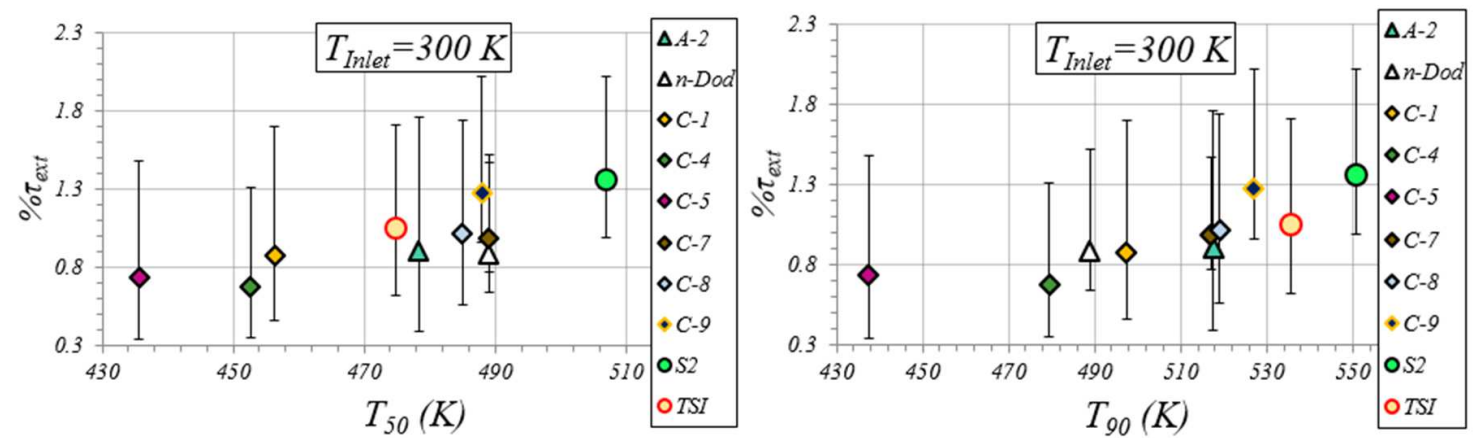

Figure 15: Average percentage of time in the near-blowoff stages $\left(\phi_{\text {event }}>\phi>\phi_{L B O}\right)$ constituted by extinction, $\% \tau_{e x t}$, plotted against $\mathbf{T}_{50}$ on the left and $\mathbf{T}_{90}$ on the right. (Condition $\mathrm{B}$ )
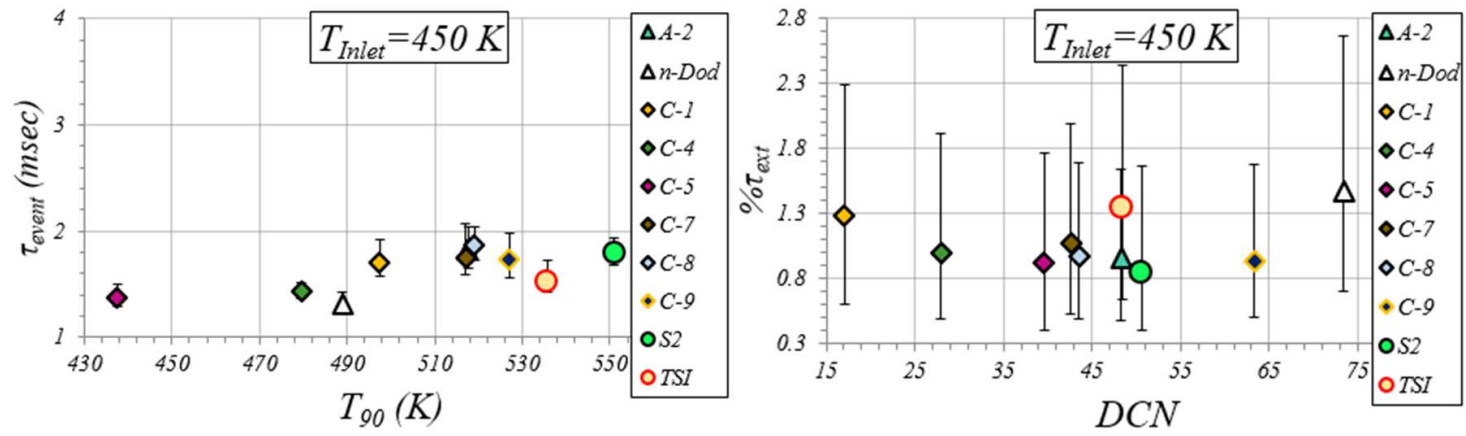

Figure 16: Average duration of the LBO precursor events, $\tau_{\text {event}}$, (left) and the percentage of time in the nearblowoff stages $\left(\phi_{\text {event }}>\phi>\phi_{L B O}\right)$ constituted by extinction, $\% \tau_{\text {ext }}($ right $)$. These condition A results are plotted against $T_{90}$ and the $\mathrm{DCN}$, respectively. 

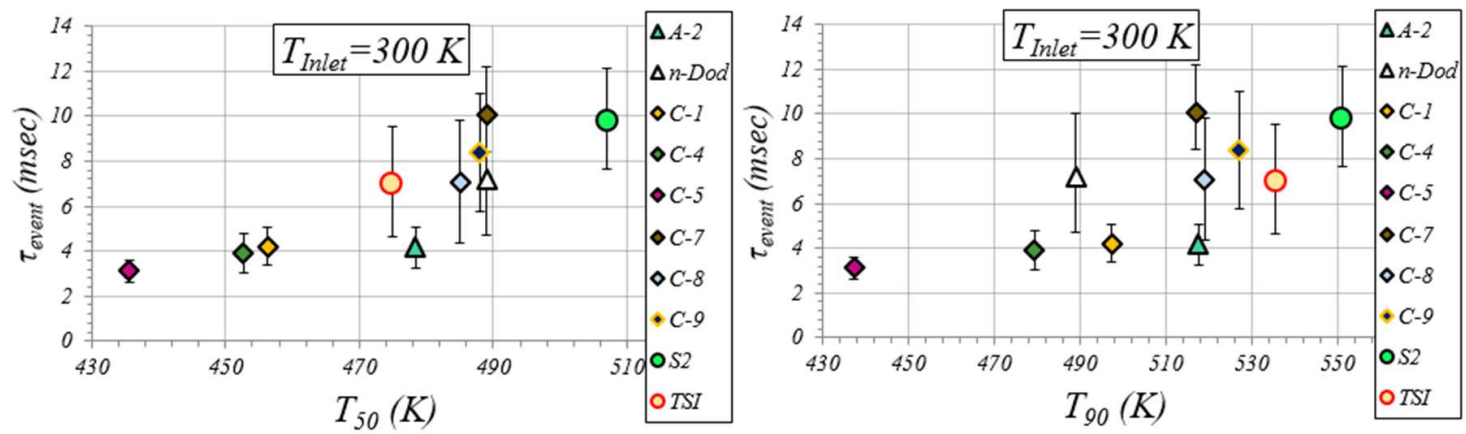

Figure 17: Average duration of the LBO precursor events, $\tau_{\text {event }}$, plotted against $\mathbf{T}_{50}$ on the left and $\mathbf{T}_{90}$ on the right. These $\tau_{\text {event }}$ values represent the average event duration in the final second before LBO. (Condition D)
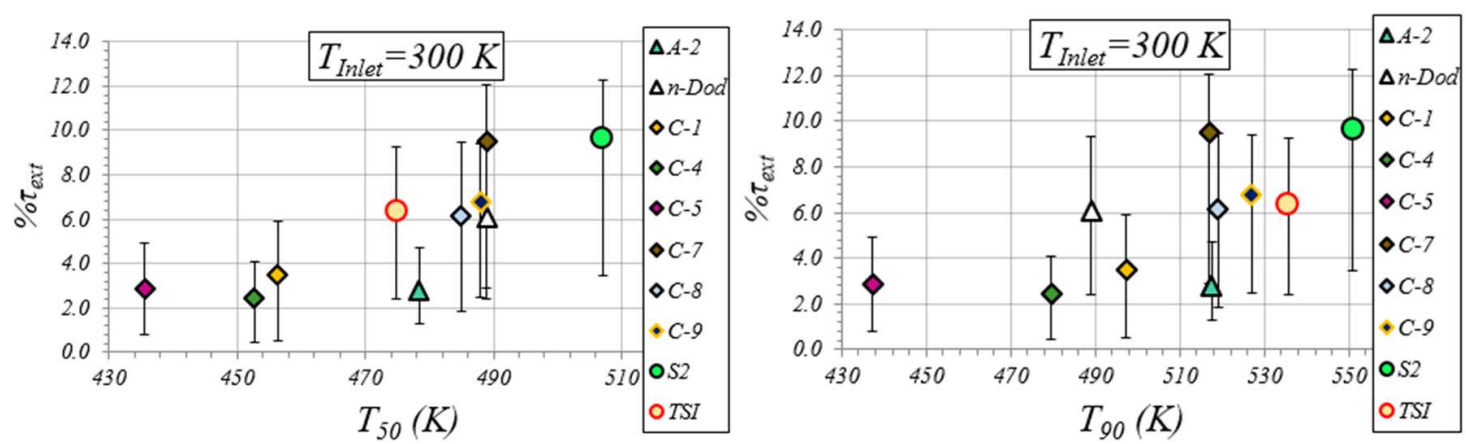

Figure 18: Average percentage of time in the near-blowoff stages $\left(\phi_{\text {event }}>\phi>\phi_{L B O}\right)$ constituted by extinction, $\% \tau_{\text {ext }}$, plotted against $\mathrm{T}_{50}$ on the left and $\mathrm{T}_{90}$ on the right. These $\% \tau_{\text {ext }}$ values represent the average extinction percentage in the final second before LBO. (Condition D)
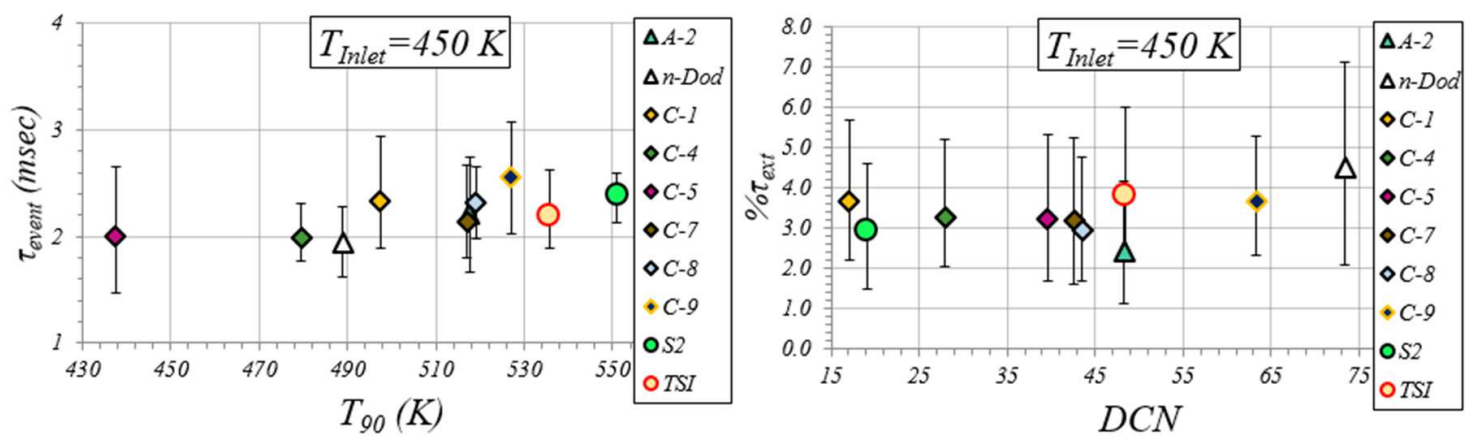

Figure 19: Average duration of the LBO precursor events, $\tau_{\text {event }}$, (left) and the $\% \tau_{\text {ext }}$ (right) in the final second before $\mathrm{LBO}$. These condition $\mathrm{C}$ results are plotted against $\mathrm{T}_{90}$ and the $\mathrm{DCN}$, respectively. 

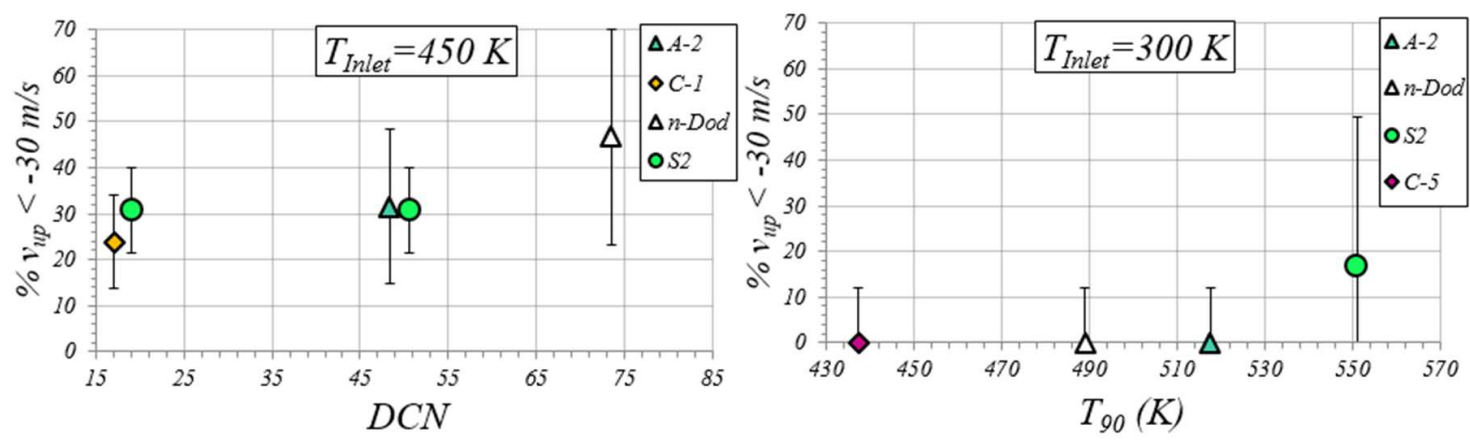

Figure 20: $\% v_{u p}<-30 \mathrm{~m} / \mathrm{s}$ at condition $\mathrm{C}$ (left) and condition $\mathrm{D}$ (right). The $450 \mathrm{~K}$ data is plotted against the DCN and the $300 \mathrm{~K}$ data is plotted against $\mathbf{T}_{90}$. Since the role of preferential vaporization on re-ignition is unclear, both the $20 \% \mathrm{DCN}$ and the DCN based on the entire fuel composition are shown for fuel S2. Error bars represent $95 \%$ confidence intervals. 